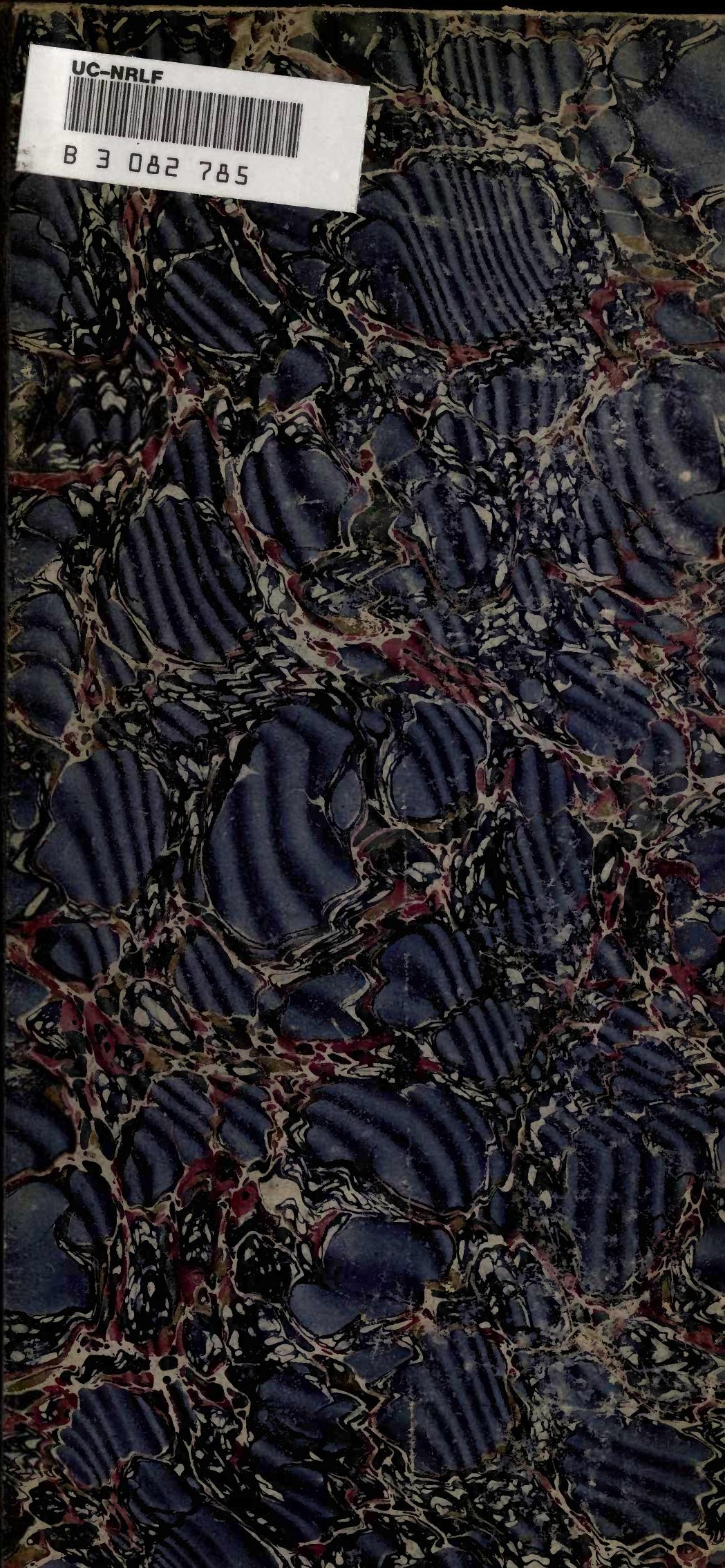




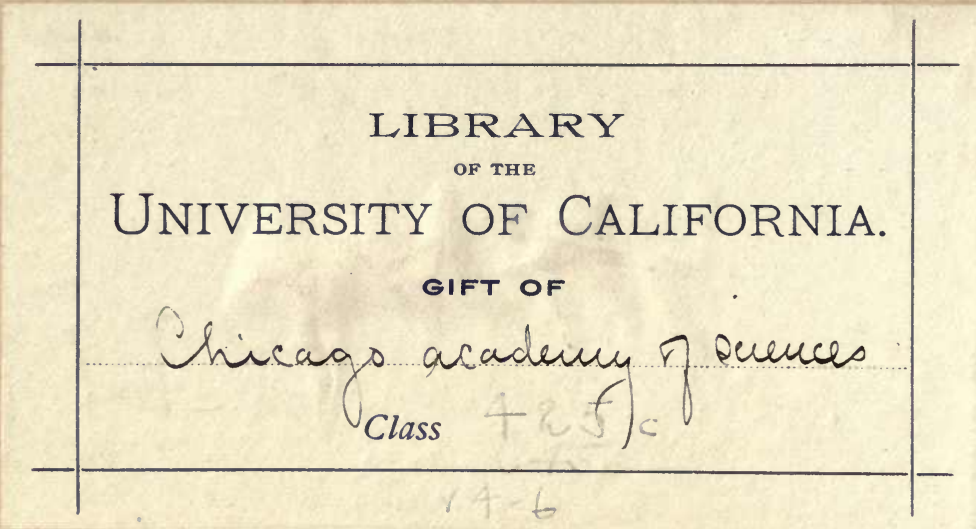




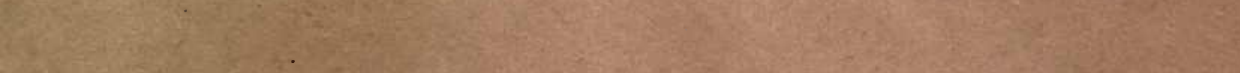

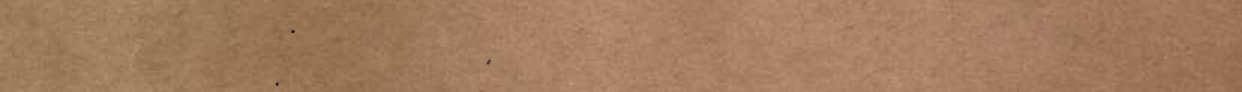

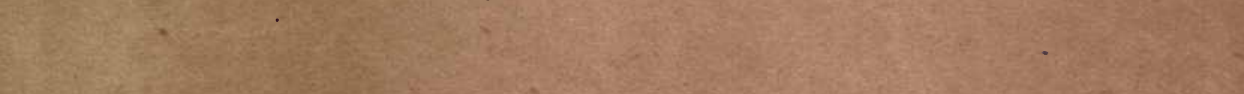

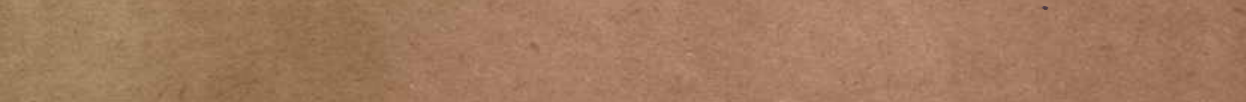

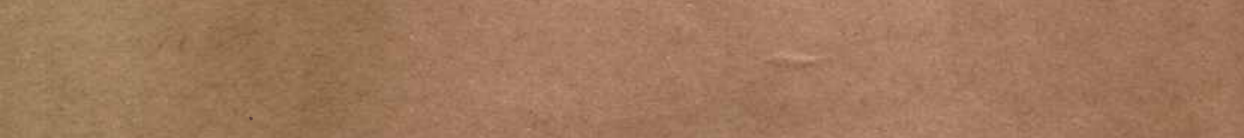

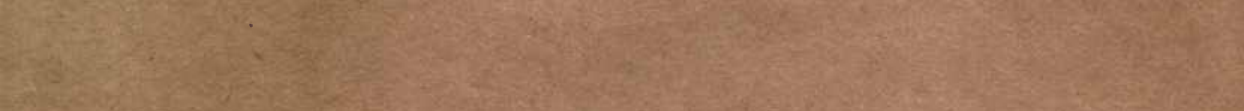

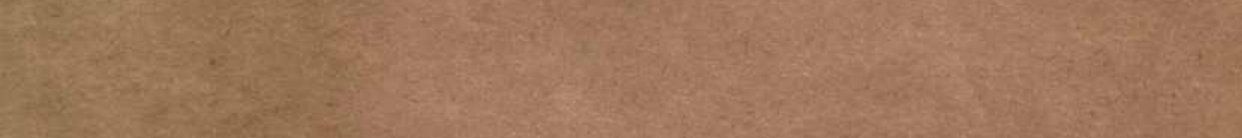

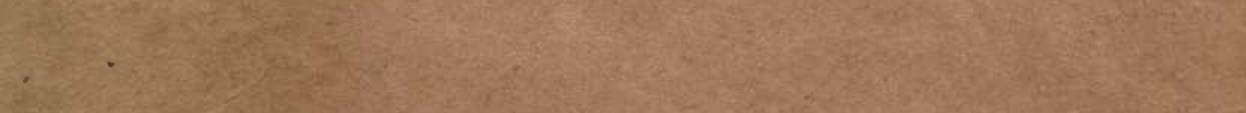

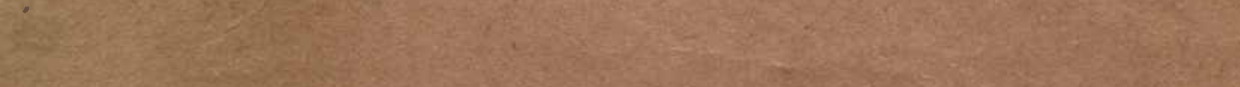

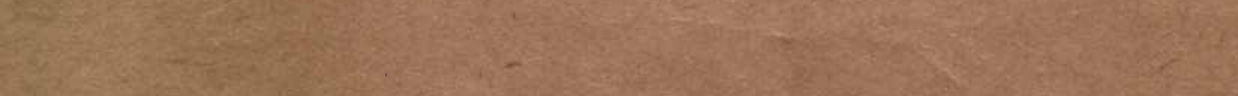

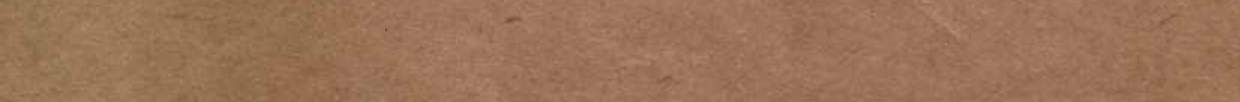

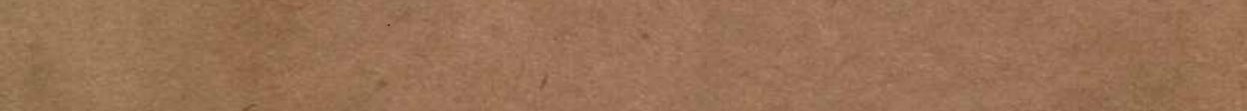
(2)

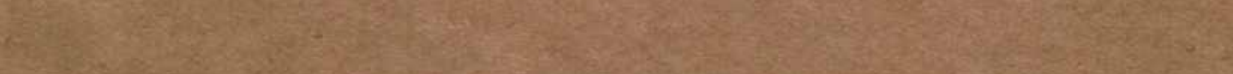

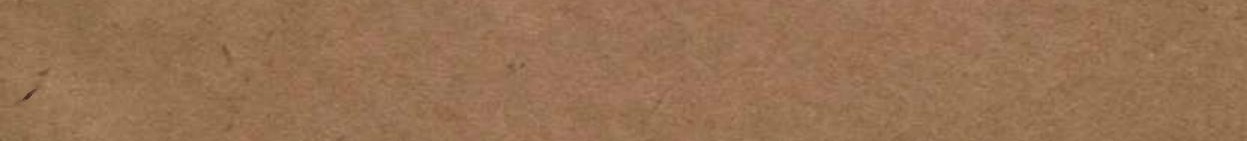

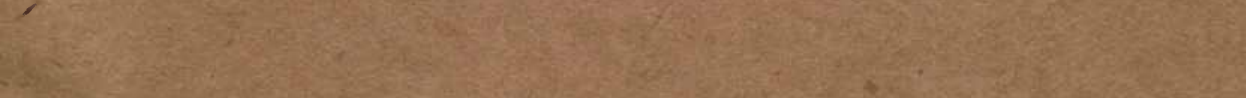
W: 






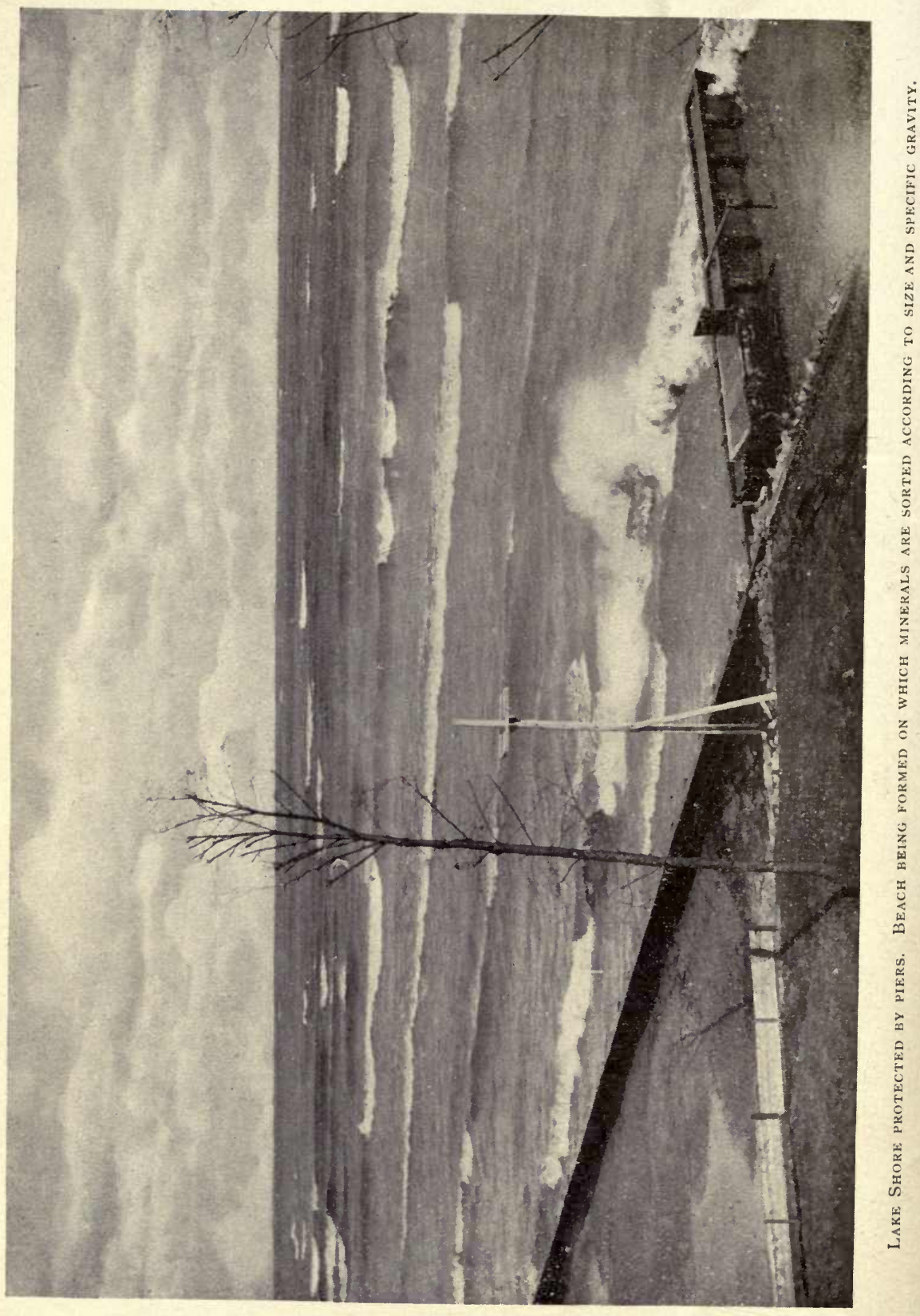




\section{The Chicago Academy of Sciences}

The Mineralogy of the Chicago Area

\section{ALJA ROBINSON CROOK}

OF THE NORTHWESTERN UNIVERSITY

\section{BULLETIN No. V.}

THE NATURAL HISTORY SURVEY 



\section{LETTER OF TRANSMITTAL}

\section{DEAR SiR:}

Chicago, Ill., March 25, 1902.

By direction of the Board of Managers of The Natural History Survey of The Chicago Academy of Sciences, I herewith submit to you for publication a report on The Minerals of the Chicago Area, prepared by Dr. Alja Robinson Crook, Northwestern University, to be issued under the rules of the Academy governing such matters, as Bulletin No. V, of the Survey.

Respectfully,

William K. HigLEY,

Chairman.

To Thomas C. Chamberlin,

President of The Chicago Academy of Sciences. 
The Board of Managers of the Geological and Natural History Survey of The Chicago Academy of Sciences:

William K. Higley, Chairman.

Charles S. Raddin, Secretary.

Thomas C. Chamberlin.

Gayton A. Douglass.

Thomas T. Johnston. 


\section{THE NATURAL HISTORY SURVEY}

The Board of Managers of the Natural History Survey take pleasure in presenting the fifth of its proposed publications. It is the third report of those relating to the geological features of the area and is devoted to the mineralogy of Chicago and vicinity.

The area covered by the survey is made to include the first great moraine which sweeps around the head of Lake Michigan, as well as several weak morainic lines lying nearer the lake. It also includes the ancient beaches of Northeastern Illinois and a portion of the outlet of the body of water which formed them. It is a country exceptionally full of varied and interesting features.

This territory is about forty-eight or fifty miles square, which after deducting the approximate area of the lakecovered portions, leaves nearly eighteen hundred square miles of land surface. It comprises all of Cook and Du Page Counties, the nine north townships of Will County and a portion of Lake County, Indiana.

While it is not a locality notable for its mineral resources, yet quite a variety of beautiful and economic forms are obtained which are of sufficient scientific value to warrant the publication of a report devoted to them.

Some of the species are emigrants and only found in the drift, yet students of mineralogy will doubtless note with interest the large number recorded and also that nearly all the mineral classes are represented.

This report has been prepared by Dr. Alja Robinson Crook, Professor of Mineralogy, Northwestern University, and represents several years of careful study and field work. 



\section{CONTENTS.}

Introduction -

Relation of Cook County Geology to its Mineralogy - I I

Where to Hunt Minerals _ _ _ _ _ _ _

Description of Species - _ _ _ _ $\quad \ldots \quad+\quad 17$

Summary

- 55

Literature on the Region Covered _ _ _ _ _ $\quad 56$

Index

$-57$ 


\section{INTRODUCTION.}

Upon first consideration, it might appear that a report upon the mineralogy of this region could be written as was the ophiology of Ireland in a book which had for chapter ten the single sentence, "There are no snakes in Ireland." But investigation shows that the region is far from being poverty-stricken either in the variety or the quantity of its minerals.

Although its rocks enclose no stores of precious metals or minerals used as gems or for ornamental work, and although lists of mineral localities do not mention Cook County, still the number of minerals that are found is great enough to accomplish several desirable results. First, they represent five out of the eight great groups or classes into which the mineral world is divided; second, they illustrate the chemical, crystallographic, optic, and other physical properties of minerals; third, they demonstrate the chief methods of investigation; fourth, some of them are of such occurrence as to make contribution to the science of Mineralogy.

Many of the minerals are beautiful and many useful for practical purposes. They are most interesting in a general way because, as individuals or in a fragmentary condition, they constitute the rocks and soil of the whole region. They are universal, and their quantity is unlimited. In their fragmentary condition, reduced to the finest powder, mingled with. organic matter, wet with water, and spread over the city streets, instead of appearing an interesting object of study, they disgust the passer-by, and worry the city fathers, so that it takes a strong imagination to follow Ruskin's suggestion, and see what minerals could result from separating and recrystallizing the various constituents in ordinary mud. The water in the mud, when freed from all foreign substances, would be sparkling, pure, distilled water. The carbon which makes the mud black, when properly separated and crystallized, would form a diamond. The silica which is usually present in such large proportions, under suitable conditions, would form a banded onyx or a purple amethyst. Then the clay would be transformed into a sapphire or the most precious of all gems-a ruby; whilc the lime might be changed into marble or a calcite 
crystal, and the magnesia, potash, soda, iron and other substances could form various minerals; until that which was so displeasing would be resolved into the most highly prized of objects.

All of these minerals have been made artificially, so the fancy is legitimate, and it may illustrate the fact that though the minerals of the region at first sight are unattractive, they do in reality contain much to reward the student. They have beauty as well as practical and scientific value. 


\section{RELATION OF COOK COUNTY GEOLOGY TO ITS MINERALOGY.}

The species found in this vicinity are such as the geological history of the region would lead us to expect. Precious metals, gems and great variety of species are not to be sought in a region whose geological history has been uneventful. In the region around Chicago, whenever any rock-layers appear in outcrops - as at Stony Island and the West Side of Chicago; or in quarries, as at Bridgeport or Rice's; or in other cuttings, like the Drainage Canal they consist of a magnesium limestone varying from a pure limestone to dolomite and containing greater or less quantities of chert nodules and different iron compounds. These layers belong to the Niagara formation of the Silurian System, and average about three hundred feet in thickness. Immediately under them are the Hudson River shales, about two hundred feet thick; underlain in turn by the Trenton limestone, 250 feet thick; the St. Peter sandstone, 200 feet thick; aud the Magnesian limestone, 400 feet thick. All of these latter belong to the Ordovician. At no place in this vicinity do the Ordovician formations outcrop. Our knowledge of them is derived from deep-well borings, of which more than a score have been made in the vicinity of Chicago. (Leverett, Water Resources of Illinois, U. S. G. S. R. XVIII. p. 800 for partial list.) Because so deeply buried and at no point appearing, they contribute nothing of importance to the minerals of the region and our source of local minerals is restricted to the Niagara limestone. Nowhere in the region have these strata been penetrated with igneous rock in dikes or laccolites or overflows. Thus, there is an absence of contact phenomena, and consequently of the complex mineral compounds and valuable metals which usually accompany contact phenomena.

Neither have the strata been subjected to such pressure or strain as to become metamorphosed. In general, they remain in nearly a horizontal position, dipping but slightly toward the lake. This slight easterly dip was well illustrated in the beds cut through by the Drainage Canal. There are exceptions to this horizontal position. If one were put down in a boat in 
the waters now nearly filling the old Stony Island Quarry (Pl. VIII, fig. 2) he would have difficulty in believing himself near Chicago. Yet so uniform are the strata in general that the region is devoid of metamorphic phenomena, and the variety of its mineral types would have been extremely limited were it not for its emigrants. Throughout the greater part of the region, the Niagara limestone, as is well known, is buried under a cover of clay, sand, and gravel, in places more than 200 feet thick. The source of much of this material has been discovered by comparison of boulders with Wisconsin, Michigan, and Canadian rocks. That the larger part of it has been transported but a short distance can be made evident in a number of ways. Four men working about thirty minutes on the lake shore at the University campus at Evanston, collecting the rocks from a pile of gravel about eight feet square, sorted them into five groups. Pl. I shows the result. The pile of limestone is in bulk somewhat more than twice that of all the other piles put together. The pile of chert is more than twice the volume of the three remaining piles united. The acid granitic rocks and the gabbros and diabases are about equal in volume, while the metamorphics play a very insignificant role, being hardly visible in the photograph. These results agree with those obtained by the writer at various by points along the lake shore, and accord with estimates given Leverett (Leverett, Pleistocene Features of the Chicago Area; Chicago Acad. Sc. Bull. 2, p. 49, et seq.) Results that point in the same direction are obtained by taking a gramme of sand and dissolving it in various acids in succession. Hydrochloric acid (hot) dissolves out the carbonates and iron oxides; some of the silicates (anorthite, hypersthene, serpentine); some phosphates (apatite); some sulphates (gypsum). The results of five analyses show $16 \%$ of such minerals soluble in hydrochloric acid. Hot sulphuric acid which would remove fluorite, zircon, biotite, takes away but $0.4 \%$ of the original mass; showing the unimportant role which these minerals play. Finally, of the minerals unattacked by the above acids and yet soluble in nitric acid (most of the metals occuring uncombined and the sulphides of which the greater part is represented by marcasite and pyrite) there are $1.35 \%$ in sand. Thus we have remaining $82 \%$ of material insoluble in the strongest acids. It is chiefly quartz. A by no means inconsiderable portion, however, is formed by rutile, garnet, 
the feldspars, pyroxenes, amphiboles, tourmaline, muscovite, talc, kaolinite. Taking into consideration the solubility of many minerals in water (for example, the haloids and some of the sulphides and sulphates) and noting the ease with which others are destroyed by the mechanical action of water, we can form an idea of the relative amounts of these minerals constituting the sand. The large percentage of quartz may be misleading, if its insolubility and toughness and hardness be forgotten. Such an error is often made. It is my opinion that Roscoe and Schorlemmer's estimate of the percentages of the common elements forming the earth's crust gives too large a figure for silicon, because the amount of quartz in the earth's crust has been overestimated. It is noticeable that when a mountain region has been peneplaned the quartz from strata many thousand feet in thickness, being the least readily soluble and least easily ground to fragments, collects in thick layers, while the potassium, sodium, calcium, iron, magnesium, aluminum silicates are pulverized and dissolved and carried away. Thus, as ane rides over an arid region, as in our western states, or in eastern Europe, where for hundreds of miles the surface is not concealed with vegetation, the thickly strewn quartz boulders and pebbles and sand give a false impression of their relative abundance. But if a section of a freshly exposed cliff be considered, a true conception of the relative amounts is obtained, because the silicious beds, as a rule, form but a fraction of the cliff. They are buried and underlain by beds of hydrated aluminum silicates or of calcium carbonates. A view of the geological scale conviys the same impression. A geological chart shows that limestone formations are as oft recurring as sandstone, and shale formations nearly as common. As sedimentary rocks are formed from igneous rocks, the same proportion between the constituents that exists in the sedimentaries will obtain in the igneous, and the sedimentaries may well illustrate the constitution of the earth's crust. A geological, rather than a chemical, view of the subject would increase the calcium and aluminum, at the expense of the silicon.

The same principle applied to the investigation of our lake shore makes possible a reliable estimate of the nature of the original material supplying the present minerals. An examination by chemical analysis and by general measurements shows that the local Silurian limestone furnishes us with the 
greatest quantity of minerals, while the drift which is composed of the materials derived from six geological systemsDevonian, Silurian, Odovician, Cambrian, Algonkian, and Archaean - and from a wide extend of country, presents the greatest variety of species.

This diversity of our minerals is further increased by the changes which the minerals often undergo, whereby secondary forms result from the original. 


\section{WHERE TO HUNT MINERALS.}

Since the greater part of the region under consideration is covered with a layer of finely decomposed mineral matter, commingled with organic matter, the underlying rock and soil is completely hidden. If this cover were unbroken, not much attention would be given to Cook County mineralogy. Coverings of humus or peat do not deter prospectors who have cause to expect the presence of valuable material. Hunters for topazes and amethysts in the Urals remove the thick covering of moss and humus in thousands of places in the hope of a zone of contact between igneous and other rock. Alaskan miners prospect in spite of the tundras. But near Chicago there are no mineral prizes, and were it not for some favorable conditions the study of the subject would not be encouraged. The mountains of rock along the drainage canal represent quite completely the mineral resources of the Niagara limestone (see Pl. II). The valleys of the Chicago River and the Des Plaines, the lake shore, brick yards, quarries, and gravel banks are very favorable for the collection of emigrant minerals. The Stony Island quarry furnishes sulphides, carbonates, and hydrocarbons. No locality is more favorable than the lake shore, however, as a hunting ground, especially in places where the lake is encroaching on the shore, as at the end of what is known as "The Ridge," near the northern boundary of Evanston where new banks are being formed, and fresh material is being exposed (see Pl. III). Some of the minerals are large enough to be collected and distinguished readily. Some are small constituents of various igneous rocks, so minute as to be collected with difficulty. In this case, the miner's pan, the magnet and the lens can be used to advantage. The bank photographed in PI. III is about twenty feet high. The lower ten feet is blue clay of a good quality. The minerals buried in it have been well protected from oxidation, and as the lake encroaches upon it these minerals fall out. The man at the left of the photo is using the miner's pan as gold miners do. The other men are armed with hammer and magnet.

The novice, in quest of minerals is usually surprised by variegated and queerly-formed specimens that resemble noth- 
ing he has examined in the mineral collection. After a little practice he is able to place them in their proper groups as members of a class not mentioned in Dana's mineralogy - the class of cement side-walks, brick, furnace slag, coal from passing vessels, and broken bottles. He sees bright yellow flakes on various rocks, and has to urge himself to classify these, not among the precious metals, but as the scratches made by brassnailed shoes. But with these artificial products set aside he soon learns to recognize the following minerals, which are arranged for consideration in the classes and groups used by Dana: 


\section{DESCRIPTION OF SPECIES.}

\section{CLASS I. ELEMENTS.}

Diamond. C.

Regular.

At various places north of Chicago diamonds have been found in the drift. Prof. Hobbs describes seventeen specimens weighing together about seventy carats. The largest weighed $21 \% 1 / 4$ carats. They are most commonly white or faintly green or yellow in color. They were found in the sand and gravel of kettle moraines or in the beds of streams. Their occurrence in seven localities north of Chicago may authorize us in expecting them nearer at hand, and in the hope of promoting their dis. covery mention is made of them here.

If a small round transparent glassy or adamantine mineral of light color is found it would be well to test its hardness. If it scratches everything available, its hardness is probably ten; and if upon weighing, it proves to be three and a half times as heavy as its bulk of water, it may be pronounced a diamond. The finding of a diamond in this vicinity, though of no financial value, might still be of interest as aiding the completion of lines leading to a possible common mother lode. These lines, as now completed by Professor Hobbs (See "Diamond Field of the Great Lakes," Hobbs, J. of Geol., Vol. VII, No. 4, 1899.) are given in Fig. I.

Graphite. C.

Hexagonal.

Carbon appears in this region as graphite in scales and flakes in metamorphic rocks, chiefly gneisses, brought down by glaciers from the north. These flakes are opaque, black in color, of a greasy metallic luster, flexible, inelastic, and soft. Their hardness is $\mathrm{I}$ in the scale. Their lack of elasticity and their extreme softness enable us to distinguish them readily from biotite flakes which are elastic and from magnetite scales which are hard. They are infusible and unattacked by acids.

Sulphur. S.

Orthorhombic.

In the interior of decomposing marcasite a crumbling mass of sulphur is sometimes found. These masses are of so slight a consistency as to make crystallographic determination impossible. The more nearly oxidized they are, the more spongy and powdery do they become. They yield sulphur fumes in closed tube, are insoluble in acid, but dissolve readily in carbon disalphide. In color they are a whitish yellow. In luster earthy. Their hardness and specific gravity are unreliable because of their chemical condition. This sulphur, being a secondary product of marcasite, which is native to the Niag- 


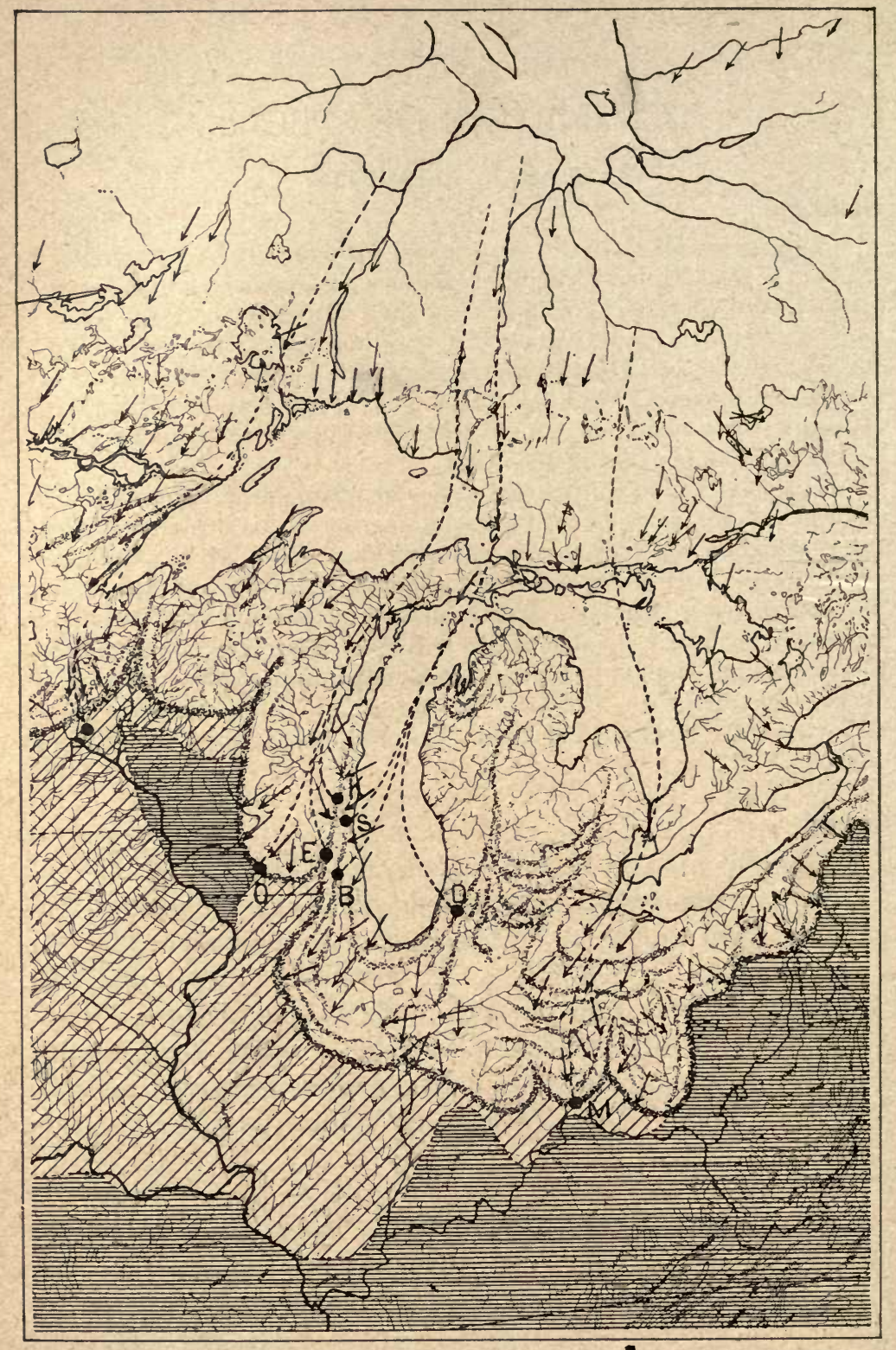

GLACIAL MAP OF THE GREAT LAKES REGION.

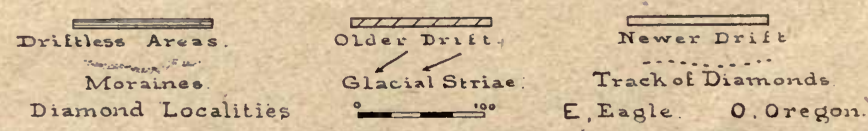

K, Kolulsville D,Dowagiac M,Miltom. P,Plum Crk. B Burington.

Fig. x. From The Journal of Geology. 
ara limestone can be classed as a native element, and it is the only one of the elements which is represented in the limestone rock of this region.

Gold. Au.

Regular.

Cook County does not escape the universal search for gold. Periodical reports of gold discoveries near Chicago appear in the papers. Material supposed to contain gold is being repeatedly sent to our assay laboratories. This supposed gold represents a great variety of substances. One of the most common is pyrites. Less commonly the samples are pieces of limestone that have been scratched by the copper nails in shoes. Sometimes they are decomposed mica, which has a reddish yellow color and is infusible in an ordinary fire. A blow of the hammer would place pyrites out of the question, for it is brittle and hard, emits sparks when struck, and gives the odor of burning sulphur. A drop of nitric acid would eat away the copper nail scratches on the marked pebbles. An attempt to wash the decomposed mica would show its light weight, for the scales are so light as to be with difficulty submerged, while gold is nineteen times as heavy as water.

Gold is present in the region, but in quantities gauged to the assayers balance rather than to the prospectors pocketbook. It is found in the lake shore sands in quantities sufficient to give a trace. Some specimens of cabinet size have been found in the drift. They have come from the north, possibly near the straits of Mackinac. Worthen reports the finding of gold flakes in drift material (A. H. Worthen, Economical Geology of Illinois, Vol.I. p. 27 et seq.). One of the best samples seen by the writer was found at Willow Springs during the digging of the Drainage Canal, and is now in the possession of Mr. L. E. Cooley. The pebble is a piece of tourmaline granite, and was deeply buried in the gravel. The gold flakes are scattered through the mass, chiefly in the tourmaline. An occasional octahedral plane is evident on some of the stringers. When attempt is made to remove the flakes, it becomes evident that they are not plastered on by the finder, as they are connected with underlying fibers that permeate the mass. They are malleable, ductile, 2.5 in hardness, and 19 times as heavy as water. A flake scorified, cupelled, treated with microcosmic salt, and immersed in concentrated nitric acid gave no reactions for silver, 
Mr. W. R. Hornbaker reports finding a pyritiferous boulder in drift which assayed yielded 5-100 ounces gold per ton and silver 48-100 ounces.

Silver. Ag.

Regular.

Small threads of native silver appear in some of the copper specimens found in the drift. They have the physical characteristics of silver, being without cleavage, being malleable and ductile, having a hardness of 2.5 to 3 , a gravity of IO.I, a whitish color, and solubility in nitric acid. Ossian Guthrie reports the finding of a silver specimen at the Sag but does not describe it. (Page 5 in "Relics Turned Up in the Drainage Canal", Journal Western Society of Engineers.)

Copper. $\mathrm{Cu}$.

Regular.

Many copper specimens have been found in the drift in various parts of the Chicago area. Guthrie gives the following list:

I. Fragments found at Drainage Canal, now at Calhoun School, $1 / 2$ pound.

2. Thirteen pound piece found at Worth distorted in stone crusher, Pl. IV, fig. I.

3. Eighteen pound piece found in the Drainage Canal.

4. Fifty-five pound piece now at the National Museum, Washington.

5. Sixty-seven pound piece.

6. Ninety-five pound piece, pressed and rolled till bent over a pebble.

7. One hundred twenty pound piece found at Dwight.

8. One hundred sixty-eight pound piece, found near the penitentiary at Joliet.

Could these pieces have fallen off of freight cars, could they have been placed where found by interested men or by Indians, or do they properly belong among the minerals characteristic of the region? Answer to these questions is found in the localities in which they were found and in their physical peculiarities. In the first place all have been found in the drift, accompanied by igneous and metamorphic rock. Some of them were a long distance from railroad or wagon road and deeply buried. They were found by different people in presence of witnesses in different localities. In the second place, upon comparison with samples of pig copper their dis- 
tinguishing characteristics become evident. They are coated with blue and green carbonates of copper-azurite and malachite. The thickness of the coating indicates many years of exposure to carbonated water. In some protected cavities cuprite crystals occur. Some of them contain crystal threads of native silver. Neither cuprite crystals nor crystallized carbonates nor silver thread are found in pig copper. Further, these specimens bear the marks of glacial transportation. They are often planed and deeply striated, and we may safely conclude that they are emigrant minerals. Copper, sometimes shows octahedral and dodekahedral planes of various sizes on capillary, wiry, arborescent or massive samples. It has no cleavage; its fracture is hackly. It is malleable. In hardness it is similar to silver -2.5 to 3 . In gravity, 8.5 to 8.9 . In color it is red. It is soluble in nitric acid.

\section{CLASS II. SULPHIDES.}

The class of sulphides is represented by at least six species in Cook County. Four of these occur in the Niagara limestone. They are as follows:

Galena. $\mathrm{PbS}$.

Regular.

In the cavities of the local limestone and in the fragments of vein quartz in the drift, are small samples of lead sulphide which illustrate the distribution of the mineral in both crystalline and non-crystalline rocks. Its associates are quartz, calcite, pyrite, sphalerite, argentite. None of the crystals show planes, but simply cleavage surfaces. In hardness they are 2.6. Gravity, 7.4. In color, reddish lead gray, lighter in fine aggregates; streak, grayish black. Luster, metallic and so brilliant that galena is called "the diamond of ores." On charcoal, decrepitates, giving sulphur fumes and a lead globule. Soluble in nitric acid.

Argentite. $\mathrm{Ag}_{2} \mathrm{~S}$.

Regular.

The silver sulphide is found in connection with galena, and as a sulphurized coating of the silver threads that occur in copper specimens. Malleable, flexible, and sectile. Hardness, 2.5. Gravity, 7. Color, dark lead grey. Poor lustre. Before the blow-pipe, swells, gives off sulphur, leaves silver bead. 
Sphalerite. $Z n$ S.

Regular.

Far more common than either of the above named sulphides is the zinc sulphide in this region. Like galena, it occurs in both the transported crystallines and in the local limestone. The planes most commonly seen are those of the tetrahedron, which are striated, distorted, twinned.

The coarse, franular masses exhibit good dodekahedral cleavage. The fracture, which is splintery, is little in evidence. The mineral is brittle, has a hardness of 3.5 , a specific gravity of 4 , and the following colors: yellow, brown, black. Its lustre is resinous, its streak yellowish brown. Before the blowpipe it fuses with difficulty, giving off sulphur fumes and coating charcoal with a white incrustation of zinc. It dissolves in hydrochloric acid.

Millerite. NiS.

Hexagonal.

In some of the sphalerite enclosed in chert appear long slender metallic yellow needles, which give under the blowpipe reactions for nickel. These yellow crystals are millerite. Dana, Naumann, and Lacroix record the association of millerite with calcite, dolomite, fluorite, siderite, pyrite, hematite, with cobalt and silver ores and with quartz. No mention is made of its occurrence with sphalerite in any literature upon the subject. This seems to be a new occurrence. The hexagonal needles are often so fine as to justify the name of "Haarkies." Often they are tufted and in confused masses. Cleavage has not been observed. They are brittle, have a hardness of $3 \cdot 5$, and specific gravity of 5.5. Brass to bronze yellow, often with grey iridescent tarnish. The color of the streak is greenish black. To test for nickel, following the method given by Bunsen (See Determinative Mineralogy and Blowpipe Analysis, p. 97), I boiled some powdered mineral with nitric acid till dissolved and about 5 c.c. of acid remained. Added water, boiled, poured in excess of ammonia, and filtered. Added caustic potash till ammonia odor was no longer perceptible. The precipitate, hydroxide of nickel, washed in hot water, then treated with borax in oxidizing flame, yielded a bead violet colored while hot, and reddish brown when cool. The presence of cobalt was not detected. Millerite is one of the rarest of Cook County minerals.

More abundant than any of the ten mineral species thus far described is: 
Pyrite. $\mathrm{FeS}_{2}$.

Regular.

It occurs both in the drift and in the native limestone of the region. In the drift it is the most usual form of the iron sulphide, whereas in the limestone marcasite, the orthorhombic form, predominates. The fitness of the name pyrite becomes evident when a specimen is struck with steel or flint, for brilliant sparks are given off. It is called iron pyrites to distinguish it from other forms of pyrites such as arsenical p. and copper p.

The pyritohedron (210), the most common form, is represented in Fig. 2. In all the specimens examined the faces have been striated, at times indistinctly, at other times in a pronounced manner. As far as observed on these specimens, the striations have been in the directions indicated in the figure, and never at right angles to this direction as is reported by Lacroix as occurring in French minerals. Usually the pyrito-

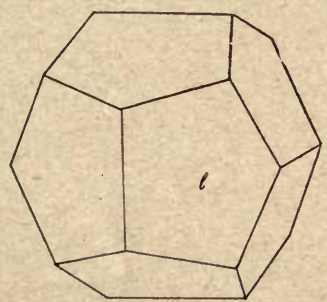

Fig. 2.

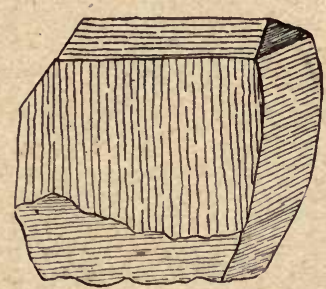

Fig. 3.

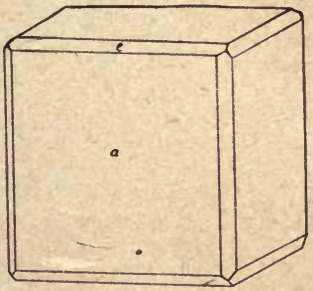

Fig. 4.

hedral faces are repeated until varying degrees of distortion result. Fig. 3 represents the building up of the planes in a crystal about one-eighth of an inch in diameter, until the front surface is flat and the other planes have nearly lost their resemblance to a pyritohedron. In Fig. 4 the operation has been carried so far that a cube has resulted. These pseudocubes are so common that in all the samples examined the cubical faces are strongly striated and the edges truncated with pyritohedral planes. Pl. IV, fig. 2 represents examples from the Niagara limestone. In the left hand specimen are a group of such cubes, disclosed after the original calcite covering has been dissolved with hydrochloric acid. The largest crystal on the right side of this specimen is that represented in Fig. 4. In the right hand specimen the calcite is left remaining. This occurrence suggests that the iron sulphide is more apt to crystallize in the regular system when the solution from which it is formed is pure. When the solution is contaminated with for- 
eign substances crystallization is retarded and the less stable form, that of marcasite, is produced. Cleavage indistinct; fracture conchoidal; brittle; hardness 6; specific gravity 4.9 to 5.2. By mixture with quartz or marcasite in microscopic inclusions or because of incipient decomposition the specific gravity sinks as low as 4.5 , which is the minimum presented by pure marcasite. This variation in the specific gravity increases the difficulty of distinguishing between the two species. Its lustre is metallic, splendent to glistening; color, pale brass yellow, nearly uniform, often bronze, rarely brightly tarnished because of oxidation. The streak is greenish black or brownish, opaque even in the thinnest sections. Very slightly magnetic (paramagnetic). Offers strong resistance to electric current; shows two kinds of thermo-electricity. Its chemistry, association and history are identical with marcasite, and as marcasite is the most abundant form in the region we shall consider the points under marcasite.

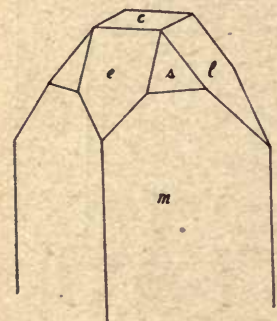

Fig. 5 .

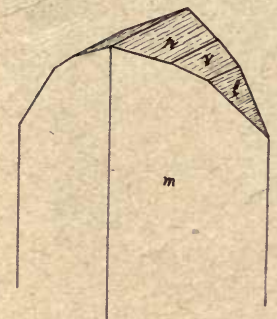

Fig. 6.

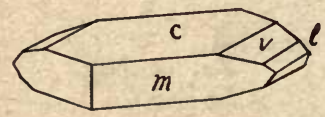

Fig. 7 .

Marcasite. $\mathrm{FeS}_{2}$.

Orthorhombic.

Figs. 5, 6 and 7 represent the type forms of marcasite, which occurs both in columnar and in tabular crystals. The prism (IIO), macrodome (IOI), clinodome (OI I), pyramid (III) and the base (OOI) are often developed while the planes most commonly appearing in Cook Co. marcasites are different brachydomes (OII), (OI2), (OI3), etc. Isolated crystals extremely rare. Usually closely crowded, interfering and polysynthetic twins, globular, botryoidal, stalactitic, radiated. The botryoidal masses are often composed of clusters of prisms ending in various brachydome planes that are almost invariably striated, as is shown in figure 6 . The end planes may be so nearly flat and may so nearly approach a square as to be mistaken for cubic planes, until the diagonal striations are observed. The striations are parallel to the brachydiagonal. Fig. 7 presents a common flat form which is usually striated 
on the domies and base. A photograph, Pl.V, fig. I, natural size, of a specimen from the limestone quarry at Bridgeport shows a drusy cavity in the limestone full of that form of marcasite known as spearhead pyrites. Fig. 8 represents the twinning which produces this form. The twinning plane is the prism. The prism planes are present only as an edge, while the clinodome planes are repeated until they produce disk-like groups resembling a spear. In Pl. V, fig. 2, the two upper specimens are groups of the form known as "comb pyrites." As seen in Fig. 9 , these are groups of twins whose twinning plane is the prism

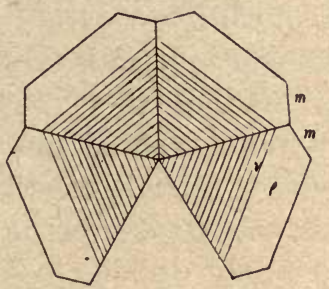

Fig. 8.

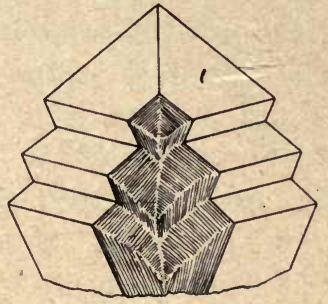

Fig. 9.

repeated in stair-like arrangement. In the lower figure of $\mathrm{Pl} . \mathrm{V}$, fig. 2 are globular masses, very often occurring in unworn and undecomposed specimens. The one at the right is on Niagara limestone. The round velvety looking masses are composed of bunches of crystals of different lengths which extended into the mother solution. The advancing front of such a growing crystal group would naturally be globular, since such a form would give each crystal the largest area of solution from which to draw material. The persistency of the spherical habit of these concretions is illustrated in Pl. VI, fig. I. When found on the lake shore these concretions may easily be mistaken for ordinary pebbles, but when a trace of the original crystal shape remains, as seen in the left hand lower specimen, the true nature of the sample is recognized. Further, these seeming common stone pebbles are much heavier than an ordinary pebble. Upon being broken open, the yellow metallic luster and the common radiate structure shown in Pl. VI, fig. 2, attract the attention. In the lower nodules the remnants of crystals left after the rolling and grinding of waves of the lake shore, and after the oxidation to which the nodules have been subjected, are still to be detected. The upper two specimens show the radiated columns and foundation from which they sprang. The center of the nodule is composed of fine 
granulated material which has solidified with such rapidity or under such unfavorable conditions that it has not been possible for the crystal molecules to arrange themselves in a manner conducive to large growth. After a suitable foundation was established, or after the mother solution was sufficiently cleared, long prisms of marcasite crowded upon each other. The cleavage of marcasite is always indistinct; fracture uneven; tenacity brittle; hardness 6 ; specific gravity 4.6 to 4.8 , being thus somewhat lighter than pyrite; luster metallic; color, greyish, greenish yellow, to pale bronze yellow, lighter than pyrite; streak, dark greenish grey; diaphaneity as in pyrite; magnetic and electrical properties identical with pyrite.

The chemical composition, association, and occurrence of pyrite and marcasite are so similar that they may best be treated together. They usually contain small quantities of arsenic, antimony, and sometimes of nickel, cobalt, copper, gold, and thallium. Gold and silver are quite commonly distributed through pyrite in such a finely divided condition as to be invisible to the eye, but yet present in such quantities as to furnish a supply of the precious metals.

These iron sulphides which are so common in all parts of the world are extremely abundant in the region under consideration. In the granite, diorites, and diabases of the drift the most usual form is that crystallizing in the regular system. In metamorphic rocks-gneiss, mica schist, amphibolite schist and slates-microscopic suspended crystals of either the regular or orthorhombic forms often follow the schistose layers. Sometimes they are so numerous as to form pale bands"Fahlbänder" - through the rocks. At other times their presence is indicated macroscopically only upon decomposition, when they yield white efflorescences of melanterite. Further, the sedimentary formations-the Niagara limestones, and the overlying clays and peat-contain both pyrites and marcasites. Iron sulphide, usually marcasite, is a common fossilizing material replacing the skin of trilobites, the stems of crinoids and the shells of mollusks. It forms incrustations on calcite geodes. In clay banks, as that shown in Pl. III, it occurs in innumerable concretions. A bed of marcasite several feet wide extended along the water's edge for 200 feet at the end of Ridge Ave., Evanston, where the lake encroaching upon the shore had caused fresh exposure of the clay and, washing out the finer materials, had left the gravels and marcasite. A portion of this 
mascasite was in the form of concretions in the clay, while the greater part had at one time been contained in the limestone fragments in the drift. Within two years - the active encroachment of the lake having been retarded by piers built into the water - the bed of marcasite was entirely decomposed or buried.

The peat of the region contains iron sulphide whose presence is evident frequently only after the formation of melanterite. This mineral covers the peat like frost. Likewise even in the protection of the museum marcasite decomposes and passes into other compounds. The Chicago Academy of Sciences, the Field Columbian Museum, and University Museums in the vicinity of Chicago, contain many fine specimens of this mineral. But they are difficult to preserve, since under the influence of moist air, the sulphide changes to the sulphate with formation of sulphuric acid which corrodes containing boxes. $\left[\mathrm{FeS}_{2}+\right.$ $\left.8 \mathrm{H}_{2} \mathrm{O}+7 \mathrm{O}=\mathrm{FeSO}_{4} \cdot 7 \mathrm{H}_{2} \mathrm{O}+\mathrm{H}_{2} \mathrm{SO}_{4}\right]$.

Decomposition of these minerals in the field give rise to other minerals whose composition is dependent upon the enclosing rock. In the clay beds and limestones of the region are formed white filaments of melanterite which change into a sulphur yellow buttery mass consisting of melanterite $\left(\mathrm{FeSO}_{4}+7 \mathrm{H}_{2} \mathrm{O}\right)$ copiapite $\left(2 \mathrm{Fe}_{2} \mathrm{O}_{3} \cdot 5 \mathrm{SO}_{3}+18 \mathrm{H}_{2} \mathrm{O}\right)$, halotrichite $\left(\mathrm{FeSO}_{4} \cdot \mathrm{Al}_{2}\left(\mathrm{SO}_{4}\right)_{3}+24 \mathrm{H}_{2} \mathrm{O}\right)$ gypsum $\left(\mathrm{CaSO}_{4}+\mathrm{H}_{2} \mathrm{O}\right)$, and siderite $\left(\mathrm{FeCO}_{3}\right)$. The presence of minute gypsum fibers and siderite crystals in the clay is due to such a transformation.

The best localities for marcasite and pyrite are the lake shore and the river valleys of this region. Large quantities were on the embankment between the Des Plaines river and Chicago Drainage Canal near Willow Springs during the building of the canal.

\section{CLASS III. SULPHO-SALTS AND CLASS IV. HALOIDS.}

These classes are not represented as far as I know in this region.

\section{CLASS V. OXIDES.}

Of this class there are at least eight species, of which the most abundant and universal representative in this region, as in all regions, is -

Quartz. $\mathrm{SiO}_{2}$.

Hexagonal.

Quartz is found both as a native and as an emigrant, and both in phanero-crystalline and crypto-crystalline varieties, see 
Pl. VII, fig. I. Neither the crypto-crystalline nor the phanerocrystalline variety is peculiar to any one source, each being found both in the drift and in the native limestone. The largest crystals found by the writer on the lake shore are in a piece of amygdoloidal melaphyre, characteristic of the Michigan copper region. They are half an inch high and three-eighths of an inch in diameter, bounded by the common striated prisms, capped by positive and negative rhombohedral planes.

The alternate rhombohedrons are tarnished with a brown coating, probably of an iron oxide. The specimens in chert nodules are also terminated with the positive and negative rhombohedrons and in many of these crystals under examination the rhombohedrons are so evenly developed as to appear to be hexagonal pyramids. This is illustrated in the specimen at the right hand upper corner of the photograph Pl. VII, fig. 2 and shown in the drawing Fig. IO. Prisms with double terminations occur more commonly in the limestone than in the drift material, see Fig. II.

Since the crystals line the wall of cavities and their long axes are perpendicular to the base on which the crystal rests, the $c$ axes form all possible angles with each other, and the

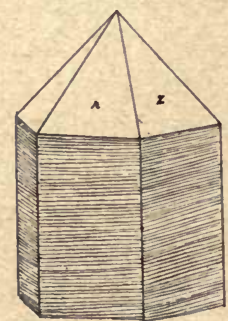

Fig. 10.

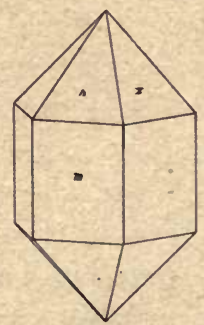

Fig. II.

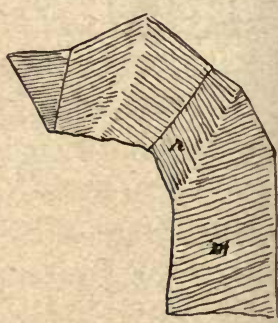

Fig. I2.

resulting groups are a confusion of interfering crystals. The direction of the $c$ axis can be distinguished by the predomi nant striations transverse to this direction. Fig. 12 represents the striations on a prism face with striations showing the directions of rhombohedrons which may be distinguished in as much as the latter forms reëntering angles with each other. The small quartz crystals lining the geode in PI.VII, fig. 2 are clear, have sharp edges and well formed planes, and show the polarization colors due to the refraction of light. The cryptocrystalline specimens are most commonly white to grey in color and translucent to opaque. They are represented by several 
forms of chalcedony, usually chert, rarely agate. The chert is conchoidal and somewhat splintery in fracture, being more splintery as the proportion of impurities increase. These impurities are chiefly varying proportions of calcium carbonate, which may become so abundant as to pass by insensible gradations into limestone. Other impurities are hydrated silicates of aluminum and small amounts of carbon and iron compounds. Chert occurs in great quantities in the limestone. Often the nodules are so numerous as to ruin the limestone for building purposes, since the point of contact between the chert and the limestone is a line of weakness. When the chert nodules are very abundant the stone is unfit even for the limekiln. Walking along the spoil banks of the drainage canal it becomes evident to the observer that the easily dissolved limestone being carried away would leave a great mass of a difficultly soluble chert, and this mass, when waterworn and acted upon by heat and cold would soon form gravel banks such as those common to the lake shore. The presence of silica in the limestone is probably due to plants and animals which, while living in the waters from whence came the limestone, secreted silica in their shells and skeletons. The remains of many of these animals and plants-seaweed, desmids, diatoms, sponges, rhizapods-can be distinguished. The right hand specimen in PI. VII, fig. I shows some of the forms of life which contributed to the formation of these rocks. The most abundant forms are cylindrical bodies of varying lengths, many of them a quarter of an inch long. some of them are straight while others are bent into bizarre forms. The body-wall is made of silica which is less perfectly crystallized than that found in the body cavities. Other forms may with great probability be classified as radiolarians (Spumellaria?) sponges (Astylospongia), crinoids (Pisocrinus, Stephanocrinus), bryozoans (Hemiphragma?) A microscopic section under crossed Nicols reveals polarization colors between the different organic forms and in the interior of these. No chert which I have examined has failed to show polarization colors. The oft repeated statement that chert is noncrystalline is a wrong one. Examination of the nodules sheds light upon the manner of their formation. Waters laden with silica deposited their burden quite rapidly at first on the bordering walls of the cavities in which the nodule was forming. This rapid deposition produced the least pure and least well 
crystallized chert. Within this rim silica in solution passed by osmosis or through crevices, and formed a purer layer. Finally in the remaining cavities the pure silica was slowly built up in well defined crystals - the form of the mineral being thus dependent both upon the purity of the mother solution and upon the rapidity of deposition. When deposition was slow and a change in direction of current brought new material into the liquor, bands were formed, and agates resulted.

Quartz exhibits no cleavage, has a conchoidal fracture, a hardness of 7 , a specific gravity of 2.5 to 2.8 , and occurs in nearly all colors. Its lustre is greasy or glassy to dull. When pure it is transparent. When impure, opaque. Before the blowpipe it is infusible, and it is insoluble except in hydrofluoric acid or caustic alkali.

Tschermak classifies hornstone with phanero-crystalline quartz on the ground of insolubility in caustic alkali. Seven varieties of quartz fragments placed in a solution of sodium hydrate and allowed to stand for two months gave the following results:

For rose quartz, chalcedonic quartz, chalcedony, and pure chert from the lake shore, there was no appreciable loss in weight, whereas for flint from England there was $0.2 \%$ loss; for an impure chert from the lake shore $4 \%$ loss, and and for opaline chalcedony $97 \%$ loss. Hence it would seem advisable to retain Dana's classification, placing chert and hornstone with the cryptocrystalline variety.

Thin sections exhibit conchoidal fracture, apatite and uifld enclosures, positive refraction, righthanded or lefthanded rotation of the plane of polarization, and brilliant interference tints.

While the sand upon the shore consists chiefly of quartz, the following analyses show that it contains many other substances as well. Results of five analyses showed 16\% of material soluble in hydrochloric acid (such as calcite, iron oxides, etc.), $0.4 \%$ soluble in sulphuric acid, and $1.35 \%$ soluble in nitric acid. There was thus left $82 \%$ of insoluble materialchiefly quartz.

Cuprite. $\mathrm{Cu}_{2} \mathrm{O}$.

Regular.

The only form of the copper oxide observed in this region occurs on those specimens of the native copper which have been described as having been found in the drift. No crystals have come to my notice. The common properties of cuprite 
are its brittleness; its hardness of 3.5 ; its specific gravity of 6 , its cochineal red color; its brown red streak; and its adamantine luster.

Corundum. $\quad \mathrm{A1}_{2} \mathrm{O}_{3}$

Hexagonal.

Andrews, Marcy, and others have reported the occurrence of frag. ments of corundum in the form of impure rubies in the lake shore sands. I have been unable to find specimens. The reported finds may have been fragments of clear garnets.

Hematite. $\quad \mathrm{Fe}_{2} \mathrm{O}_{3}$

Hexagonal.

This form of the iron oxide occurs as one of the phases in the transformation undergone by iron compounds, notably magnetite. It is found here in plates and incrustations. When in massive pieces, such as occur in the drift, it is often micaceous or compact. Red ochreous varieties occur in balls in the clay. When in hard brown argillaceous masses it is known as clay iron stone. It exhibits a conchoidal fracture, a hardness of 5.5 to 6.5 , and a specific gravity of 5.3 . Its colors are red, grey, or black. Its streak is cherry red to brownish red. Its luster is metallic or earthly. It is soluble in hydrochloric acid and before the blowpipe yields a magnetic globule. It is the great paint of nature, and gives color to the many rocks of the region. There are no deposits here that are concentrated enough to be of practical value.

Ilmenite. $\mathrm{FeTiO}_{3}$

Hexagonal.

Very commonly with other iron and titanium ores there are found in the drift crystals of ilmenite. Their hosts, are usually diorite and gabbro, in which the ilmenite assumes the place of magnetite. It may be separated from the other lighter minerals in the sand by panning. Its hardness is 6; its specific gravity 5 ; its luster and color similar to magnetite; its streak brown and submetallic thus differing from that of magnetite; it is opaque in the thinnest microscopic sections. It is slightly magnetic. The best means of distinguishing it from the iron oxides are the chemical tests. With borax in the reducing flame its bead is brownish red. Tin added to the bead changes it to a violet red.

While the four last mentioned species are unimportant representatives of the minerals of the Chicago area, the follow= ing mineral may rank as one of the leading species: 
Magnetite. $\mathrm{Fe}_{3} \mathrm{O}_{4}$.

Regular.

This mineral occurs in considerable quantities in various parts of the county. It is most in evidence in the sands of the lake shore, where it has been segregated by the action of the waves, which, beating upon the shore, sort the materials roughly according to solubility, specific gravity and size. Broad bands of black material are seen stretching along the sands, sometimes continuously, sometimes in disjointed patches. If continuous, they would form deposits of economic importance, and companies have been organized for their exploitation, but there are no deposits of such a size as to be of any promise. The result of several experiments with lake shore sand collected upon the university campus at Evanston, gave an average of two per cent magnetite. The method of separation here would be that which was used by Edison upon the magnetic sand of the New Jersey coast. A horseshoe magnet drawn through the sand quickly becomes covered with a brush of magnetite. The grains forming the brush are so small as to require the use of a lens for distinguishing them. A low-power microscope, (say forty diameters), is sufficient for the most favorable study of the grains. The grains show prevailing octahedrons with rounded edges, due to the attrition of the grains upon each other. The individual planes are often pitted as is so commonly the case with meteoric iron. Sometimes they are brilliantly tarnished, at others oxidized into limonite or into red hematite. The cleavage is octahedral; the fracture, conchoidal; hardness, 5.5 , to 6.5 ; specific gravity, 5 . The color is iron black; the streak, black; the lustre, metallic; one of the most opaque of minerals, even the thinnest sections allowing no light to pass through. Powder soluble in hydrochloric acid, infusible before the blow pipe. One of the most magnetic of minerals. Its magnetism is neither a function of direction nor of size. Particles that pass through a one hundred-mesh sieve, do not differ from the coarsest grains. Its magnetism decreases with oxidation.

To bring grains of magnetite into position for study under the microscope, it is only necessary to place them in a drop of water on an object glass, cover, and draw a needle over the glass. The attractive power of the needle is enough to draw the grains into position.

Microscopic sections of metamorphic and igneous rocks - of the drift show magnetite grains as common accessory con- 
stituents. These grains are especially numerous in a hornblende schist that occurs in quantities in various places. These rocks are especially liable to disintegration, and their constittuents are dissolved and segregated by the action of water.

Rutile. $\mathrm{Ti}_{2} \mathrm{O}_{4}$.

Tetragonal.

The microscope reveals as occasional inclusions in quartz and in biotite reddish needles of rutile. They are slender acicular crystals often several hundredths of a millimeter in length. Their cleavage is parallel to the primary and the secondary prism. Their fracture is subconchoidal to uneven. They are brittle, their hardness is 6 and their specific gravity 4.2. Their lustre is metallic, their color reddish brown, and their streak pale brown. Transparent to opaque. Insoluble and infusible.

Limonite. ${ }_{2} \mathrm{Fe}_{2} \mathrm{O}_{3}+3 \mathrm{H}_{2} \mathrm{O}$.

Orthorhombic.

Bauerman and Wallerant call limonite an amorphous mineral. Dana says that it is not crystallized. Naumann says that, it is microcrystalline and cryptocrystalline. Klockmann says the crystal form is unknown. Tschermak says that it is crystalline, but does not occur in crystals. Groth classifies it as orthorhombic. Those ăuthorities which call limonite amorphous are evidently describing the rapidly precipitated iron oxide such as is found in the bottom of ponds, mixed with other substances, or the incrustation produced by rapid deposition of the hydrated iron oxide or the form known as iron rust. These forms should not be taken to represent the mineral any more than limestone should stand as representative of calcite.

When the crystallography of the mineral is discussed, that occurrence should be considered which represents the purest and most homogeneous occurrence of the mineral. If we consider this condition of limonite we find it in dense or fibrous masses, composed of long thin acicular crystals, which together build up rounded mamillary, botryoidal, reniform, or stalactitic groups. Groth's classification of them as orthorhombic is undoubtedly the correct one. Hardness, 5; gravity, 3.6 to 4 ; lustre, silky, submetallic, greasy, dull to earthy; color, various shades from black to brown; streak, yellowish brown. Opaque. Yields water in closed tube and turns to hematite. Soluble in hydrochloric acid. Found in all parts of the county as coloring matter in the soil; can be seen as an iridescent 
scum on the surface of the water and as a rusty yellowish deposit on the bottom of small ponds. Occasional fragments in the drift.

\section{CLASS VI.-OXYGEN SALTS.}

The class of Oxygen Salts is represented by several species in each of the groups of carbonates, silicates, phosphates and sulphates. Five carbonates occur in greater or less abundance.

Calcite. $\mathrm{Ca} \mathrm{CO}_{3}$.

CARBONATES.

The most abundant and characteristic carbonate of the region is calcium carbonate. It is found in a great variety of forms and associations. The pure calcium carbonate with varying quantities of magnesium and iron vicariously replacing the calcium and with various mechanical impurities such as clay and sand mixed through the mass, forms the floor rock of this region. It is of great economic importance as the source of building stone, constructional material, and road metal. In the limestone are found veins of the pure calcite which illustrate the crystal form and the cleavage. The commonest forms are those known as " nail head spar," "dog-tooth spar " and the rhombohedral cleavage pieces. Pl. VIII, fig. I shows six scalenohedral crystals of "dog-tooth spar," found at Stony Island. The prevailing form is that of the most commonly occurring scalenohedron $\rho(2 \mathrm{I} \overline{3} \mathrm{I}) \mathrm{R}_{3}$ (Fig. 13.) These planes are usually rounded by repetition of the scalenohedrons and the rhombohedrons. Often the positive rhombohedron $\mathrm{R}$ bevels the scalenohedron. The negative rhombohedron (oI $\overline{1} 2$ ), - $1 / 2 \mathrm{R}$,(Fig. I4) occurs in multitudes of sharply formed crystals in cavities in limestone. Fig. I 5 represents the crystal number two

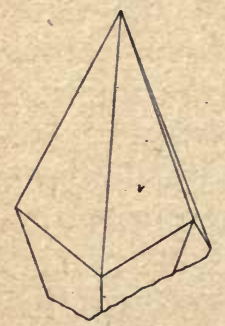

Fig. 13.

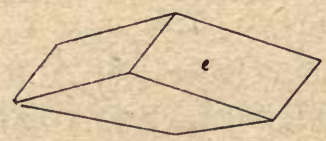

Fig. 14.

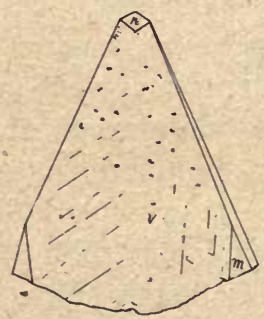

Fig. 15.

from the right of the photograph Pl. VIII, fig. I. It is about $5 / 8$ of an inch high. The scalenohedron planes are deeply pitted so that goniometric measurements lack accuracy. The planes 
are $\rho(2 \mathrm{I} \overline{3} \mathrm{I}), \rho 40 \overline{4} \mathrm{I}$, and $\rho \mathrm{IO} \overline{\mathrm{I}} \mathrm{I}$. The angle between $2 \mathrm{I} \overline{3} \mathrm{I}$ and $3 \mathrm{I} \overline{2} \mathrm{I}$ is nearly lacking. The mean of three measurements gave for the angle between $2 \mathrm{I} \overrightarrow{3} \mathrm{I}$ and $\overline{2} \mathrm{I} \overrightarrow{3} \mathrm{I} 74^{\circ}$; between $\mathrm{IO} \overline{\mathrm{I}}$ and $\overrightarrow{\mathrm{I}} \mathrm{IOI}$ $75^{\circ} \mathrm{I}$ and between IOII and $40 \overline{4} \mathrm{I} 35^{\circ}$. Cleavage traces parallel to OI I I appear on $3 \bar{I} I$ I and edges of the rhombohedrom o4II on $2 \mathrm{I} \overline{3} \mathrm{I}$.

Some of the best developed crystals are those which were found on the east wall of the quarry at Stony Island. A view of this quarry looking north is given in Pl. VIII, fig. 2. These crystals have been formed in the cavities in the limestone, and after their deposition was complete they were covered and protected by the bituminous residue of the petroleum which passed through the same cavities. The hydrocarbon compounds occupied the cavities subsequently to the calcite mother liquid, since in no case has the asphalt been enclosed in a calcite crystal. The scalenohedrons stand out through the asphalt which surrounds their base Pl. IX, fig. I. They are rounded, pitted and striated, showing that their growth has been irregular and that as deposition began upon one spot on a face, a current was started in that direction, so that the molecules were carried through the watery solution toward that point, causing a more rapid growth of that plane. As the material upon that radius became more attenuated, a new current would be established from a direction of greater concentration of calcium carbonate and a new plane would grow rapidly. Thus ridged planes were produced. Subsequently, the planes were attacked by carbonated waters poor in calcium, which produced etching and corrosion of the faces and edges.

Sometimes the cavities in the limestone are formed by the dissolution of fossil shells that once occupied the rock. The right -hand specimen in Pl. IX, fig. 2 shows a calcite crystal partly filling a cavity once occupied by a zaphrentis. This crystal illustrates the manner of crystal growth. The lower portion was so rapidly formed as to be without definite shape. As deposition progressed, it took place more slowly and the upper part of the crystal was well formed. Usually crystals crowd upon each other so that the bounding planes are obliterated, as is shown in the left hand figure in Pl. IX, fig. 2. The cleavage of calcite parallel to $\mathrm{R}$ is perfect. Its fracture is brittle. Its gravity 2.6 to 2.8 . Its hardness 3 . It may be colorless or white or gray, blue green, yellow, red, brown, black. The chief coloring materials are salts of iron, copper, 
or bituminous substances. The lustre is vitreous or greasy. Before the blow pipe it is infusible. It is soluble with effervescence in hydrochloric acid, even though the acid be diluted to one-third its strength.

The average constitution of the concretionary limestone at Bridgeport is given in the Economical Geology of Illinois, V. I, p. IO3, as being practically the following:

Insoluble silicates or sand ........ $0.42 \%$

Oxides of iron and alumina....... 0.53

Carbonate of lime ........... 57.54

Carbonate of magnesia by loss..... 41.50

Total .................... 100.00

Dolomite. $\mathrm{CaMgCO}_{\S}$

Hexagonal.

In crystal habit this mineral closely resembles calcite. All the crystals observed are minute, and composed of rhombohedra, $-R$ and $-1 / 2 R$. They incrust crevices and line cavities, often presenting stalactitic forms. In chemical composition they are identical with the rock upon which they rest, but they are without the foreign substances, such as sand grains, clay pellicles, and mica flakes. The calcium or magnesium is often replaced partly by iron. Upon oxidation, this mineral becomes brown. At other times in color it is white or reddish or greyish. In luster it is vitreous and translucent. It cleaves as does calcite quite perfectly parallel to the rhombohedron. Its fracture is subconchoidal. Its tenacity brittle. Its hardness somewhat greater than calcite, being from 3.5 to 4.0 . Its specific gravity is 2.8 to 2.9. Fragments dissolve slowly in cold hydrochloric acid and do not effervesce save when powdered. Being thus less vigorously attacked by hydrochloric acid than is calcite, it is readily distinguishable from that species. The presence of magnesia is not easily detected by blow pipe tests, nor by physical means of investigation, since dolomite is but slightly harder than calcite and but very little heavier. The crystal habit and optical properties of the two species are nearly identical. Consequently, in the only determinations which I have made for the purpose of detecting magnesium, I have dissolved the mineral in hydrochloric acid, precipitated the iron by a drop of nitric acid, diluted with twice the volume of water, added ammonia to excess, precipitated the calcium with ammonium 
carbonate, filtered and precipitated magnesium with sodium phosphate. The amount of magnesium was found to vary in different specimens. A very large percent being found in dark colored small crystals lining cavities in the limestone found on the lake shore. Smaller percents were found in crystals coating a cellular limestone from the drainage canal, and none was present in calcite crystals imbedded in the asphalt which was collected at Stony Island.

Siderite. $\mathrm{FeCO}_{3}$.

Hexagowal.

Siderite occurs as incrustations on the Niagara limestone. All the specimens observed are too imperfect to illustrate the crystal habit or the physical characteristics of the mineral with any degree of perfection. Noticeably in the calcium and magnesium carbonates does the presence of the iron carbonate increase the specific gravity, which, for dolomite is 2.8 to 2.9, while for siderite it is 3.8 . The hardness of siderite is 3.5 to 4.0. Its color is usually grey, brown, or brownish-red. It becomes magnetic upon ignition, and effervesces in acid.

Aragonite. $\mathrm{CaCO}_{3}$

Orthorhombic.

The specimens which seem to belong to this species thus far found are too small to permit of adequate determination. Some of the stalactites which by their radiated structure suggest one of the common occurrences of aragonite gave by the above described method for the detection of magnesium results which would place the stalactites with dolomite, but none of the literature on the subject describes dolomite as occurring in stalactites. Further examination, however, would be necessary to determine whether these stalactites disclose biaxial properties such as are necessary for aragonite. Here and there on the stalactites are microscopic crystals of an iron sulphide, and these increase the amount of iron in the analyses. Aragonite resembles calcite in physical properties and occurrence.

Malachite. $\mathrm{CuCO}_{3} \cdot \mathrm{Cu}(\mathrm{OH})_{2}$.

Monoclinic.

The only occurrence of this mineral in the region under consideration is illustrative of its genesis and relation to other forms of copper. It appears as a light green coating on the native copper specimens found in the drift. This is another illustration of the metamorphism which produces copper carbonate on the exposed parts of veins composed of chalcopy- 
rite, chalcosite, native copper, etc., and that which produces the green rust (Aerugo nobilis) on old copper domes on buildings, antique copper coins, and on bronze vessels.

Azurite. $2\left(\mathrm{CuCO}_{3}\right) \cdot \mathrm{Cu}(\mathrm{OH})_{2}$.

Monoclinic.

This form of the copper carbonate, which is less stable than the above described, crystallizes more readily than does malachite, and the crystals are usually in short columns or tablets. Its cleavage is complete, parallel to the clinodome. It is brittle, its fracture uneven. Its hardness is 3.5 to 4.0 , its gravity 3.7 to 3.8. Its luster is glassy, its diaphaneity translucent to opaque. Its color is azure blue, and its streak a lighter blue. Blowpipe reactions similar to those of malachite. It occurs with malachite as an incrustation. Azurite changes readily to malachite, the more stable form, by the loss of $\mathrm{CO}_{2}$ and by the gain of $\mathrm{H}_{2} \mathrm{O}$.

Thus $2\left[2\left(\mathrm{CuCO}_{3}\right) \cdot \mathrm{Cu}(\mathrm{OH})_{2}\right]+\mathrm{H}_{2} \mathrm{O}=3\left[\mathrm{CuCO}_{3} \cdot \mathrm{Cu}(\mathrm{OH})_{2}\right]$

$$
+\mathrm{CO}_{2} \text {. }
$$

SILICATES.

We now come to a division of the Oxygen Salts composed entirely of emigrants. The number of the species represented in this division is about 15 . And these occur in innumerable quantities forming the bulk of the material which buries the Niagara limestone over most of the region to the depth of a hundred feet or more. It is the second division of the Oxygen Salts, and consists of the Silicates.

The most abundant representatives of the silicates are found in the FELDSPAR GRoup, comprised of both the monoclinic and triclinic sections. All of the crystals which I have examined are in various drift boulders. While they do not represent the crystallography of the species when studied macroscopically, they do show other physical characteristics, such as hardness, specific gravity, color, and luster, and when made into thin sections and studied under the microscope, their crystallographic and optical properties can be observed. These different feldspars resemble each other very closely. While they occur in two different crystallographic systems, their external form and their angle of cleavage differ but slightly. The prism angle being nearly $60^{\circ}$ and the angle between the base and the pinacoid plane about $90^{\circ}$. Their general habit and twinning methods are similar. All have two directions of perfect cleavage, one parallel to the base and the other par- 
allel to the clinopinacoid (brachypinacoid) and nearly at 90 degrees to each other. Their hardness is 6.0 to 6.5 , their specific gravity 2.5 to 2.9. Their color is usually light. When pure they are colorless, and their common coloring matter is some salt of iron or copper or titanium, which makes them various shades of yellow, green or red. They melt before the blowpipe to a clear glass and color the flame in accordance with their composition. All are aluminum silicates of sodium, potassium or calcium, and sometimes barium. I have detected no barium in Cook County samples.

The principal part of igneous rocks consists of feldspar; and clays, shales and slates consist of pulverized and decomposed feldspar. Optical and blowpipe tests show the following species in the rocks of this region:

$\begin{array}{lll}\text { Orthoclase } & \mathrm{KAlSi}_{3} \mathrm{O}_{8} & \text { Monoclinic } \\ \text { Soda Orthoclase } & \mathrm{KNaAl}_{3} \mathrm{Si}_{3} \mathrm{O}_{8} & \text { Monoclinic } \\ \text { Microcline } & \mathrm{KNaAlSi}_{3} \mathrm{O}_{8} & \text { Triclinic }\end{array}$

Plagioclase

$\left.\left.\begin{array}{l}\text { Oligoclase } \\ \text { Labradorite }\end{array}\right\} \quad \begin{array}{l}{ }^{\mathrm{n}} \mathrm{NaAlSi}_{3} \mathrm{O}_{8} \\ \mathrm{CaAl}_{2} \mathrm{Si}_{2} \mathrm{O}_{8}\end{array}\right\} \quad$ Triclinic

\section{Orthoclase.}

Some of the best specimens of the orthoclase occur in a garnetiferous granite found in boulders at the brick yard near South Evanston. The crystals are white and but slightly decomposed. They show even cleavage planes which have a pearly to vitreous luster. Under the microscope Carlsbad twins are evident, and the crystals show but slight kaolinization. In specimens from the lake shore decomposition has proceeded so far that the optical properties are obscured. The mineral has low relief and interference colors lower than quartz, because of its slight refraction. On fresh surfaces the hardness is 6 . Its specific gravity is 2.5 . The specimens are well examined by blowpipe tests. By holding some of the finely pulverized mineral on a platinum wire in the Bunsen flame and repeatedly moistening with hydrochloric acid, if calcium is present it will appear as a green flame through green glass. No calcium is present in the orthoclase under examination. Some of the powdered mineral is mixed with an equal volume of gypsum, when through a blue glass potassium present will give a violet colored flame. In this orthoclase the potassium flame is very strong. The sodium flame is orange 
and through green glass orange yellow. All of the specimens examined show some sodium. The greater the amount of soda the more easily does the mineral fuse. It is unacted upon by acids. Orthoclase decomposes easily when attacked by carbonated or alkaline waters, and frequently the decomposition proceeds until soda and potash are completely washed away, leaving only the aluminum silicate. If the transformation has proceeded but part way, so that about $1 / 3$ of the potassium remains, muscovite may be produced. The potassium lost in these transformations passes in the form of a carbonate in solution over to a gypsum or other sulphate, and forms potassium sulphate, whieh readily furnishes the amount of potassium necessary for plant growth. Hence decomposing feldspars produce a fertile soil.

\section{Microperthite.}

Several specimens of a flesh-red feldspar yield such reactions for sodium as to suggest that the intergrowth of various lamellae, giving to the specimen the structure of microcline. These lamellae consist of orthoclase and albite leaves such as form the vraiety of feldspar known as microcline perthite.

\section{Microcline.}

Microcline crystals very closely resemble orthoclase both in form, color and chemical reaction, but microcline consists of numberless thin lamellae which form repetition twins parallel to the clinopinacoid (OIO), and show on the lustrous base (OOI) and the brachydome (IOI) very fine striations parallel to the edge formed by the meeting of the base and the brachypinacoid. There are also lamellae parallel to the macropinacoid (100) which are especially evident on sections parallel to the base (OOI) in polarized light. These are thin sheets of orthoclase or albite, and they cause the characteristic latticed texture seen under crossed nicols. This mingling of orthoclase and albite is so common as to appear in many orthoclases in granites and gneisses. The cleavage angle between the base and the brachypinacoid is only $30^{\prime}$ less than a right angle. In orthoclase it is a right angle. Sections parallel to the base under the microscope show an extinction angle with the edge formed by base and brachypinacoid as high as $15^{\circ}$, while orthoclase has parallel extinction. Sections parallel to the brachypinacoid are similar to those of orthoclase. Tschermak 
(Lehrbuch, d. Min. I894, p. 47I,) calls the two minerals heteromorphous. Hintze (Handbuch der Min:, I897, Vol. II, p. I,335) states that a separation of potassium feldspar into monoclinic and triclinic is not possible. Dana, (Text Book, Min. 1899, p. 374), recalls the statement made by Mallard and Levy more than a quarter of a century ago that orthoclase and microcline are essentially identical.

\section{Plagioclase.}

The plagioclase feldspars are represented by several varieeties, chiefly by oligoclase and labradorite. They have the same planes as orthoclase and angles which differ but slightly from that species. They are, however, triclinic. The base

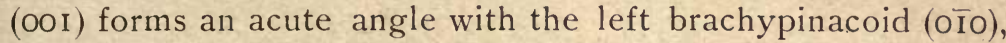
and an obtuse angle with the right brachypinacoid (oro). The pyramid and dome planes sometimes are developed on one side and not on the other, thus showing the unsymmetrical character of the crystals. Carlsbad, Baveno and Manebach Laws of crystallization obtain with this species, but the most common law of crystallization is that known as the albite law, which shows on a section parallel to the base multitudes of thin lamellae parallel to the brachydiagonal. When we have twinning according to the Pericline law, that is, parallel to the macrodiagonal, the polysynthetic striations are evident on the brachypinacoid and on the basal plane as striations at right angles to those of the albite law, and this causes grating structure as seen in microcline. The cleavage parallel to the base and brachypinacoid is perfect; parallel to the lefthand prism, imperfect. Because of the twinning parallel to the edge made by the base and brachypinacoid, the basal plane often appears striated, and this is so characteristic that when seen causes us to pronounce the species a plagioclase. Hardness, 6, specific gravity, 2.6 to 2.7. Colorless when pure, colored by enclosures grey, green and red. These are soda lime feldspars. Some of them show as high as $25 \%$ of calcium and have been classed as oligoclase, while others show nearly $75 \%$, and are classed as labradorite. (See. Szabo "Trennung's Methoden"-Pest, '76). The specimen determined as oligoclase was insoluble in acid, while that pronounced labradorite was slightly soluble. The oligoclase fragments melt more easily than do orthoclase. The containing rock is a diorite porphyry. Labradorite occurring in this region exhibits no play of colors. The blue and 
green which are predominant colors, are due to polarization phenomena dependent upon the lamellar structure. The pearl grey yellow and red colors are are due to clouds of the finest microlites of ilmenite, hematite, pyroxene, etc.- the color varying not only as the species of the microlites varies, but also as their positions vary in regard to the vertical axis of the crystal. (See Hintze, 1. c., Vol. II, p. 1,512.) The containing rock is a gabbro or diorite. Labradorite splinters melt more easily than those of oligoclase. Powdered labradorite decomposes in warm hydrochloric acid. Labradorite easily metamorphoses to epidote. In a specimen examined, the change has begun to color a large crystal with a greenish hue, and has given the specimen an oily lustre, so that it was mistaken for a specimen of nephelite.

The Pyroxene and Amphibole Groups are represented by both orthorhombic and monoclinic species, but as in the case of the feldspars, all the material at hand has been collected from the igneous drift rocks of the region, and the study and determination of the species is carried on chiefly by microscopical and chemical means, rather than by macroscopical and physical.

\section{Hypersthene. $(\mathrm{FeMg}) \mathrm{SiO}_{3}$}

Orthorhombic.

The same gabbro in which labradorite is found contains small brown crystals of hypersthene which show perfect cleavage parallel to the brachypinacoid (oro), and distinct cleavage parallel to the prisms (IIO) and the macropinacoid (IOO). The fracture is uneven, the tenacity brittle, the hardness 5 to 6 , specific gravity 3.4 to 3.5 . The cleavage surface shows a pearly or metallic luster. The color is a dark brownish green or greenish black. The streak greyish to brown. Translucent to opaque. Under the microscope and in polarized light which vibrates parallel to the $a$ axis the mineral appears brownish red, while if the light vibrates parallel to the $b$ axis, the mineral appears reddish yellow and if parallel to the $c$ axis the mineral is green. The metal-like luster of the mineral is caused by minute tabular scales of metallic enclosures, such as göthite, hematite, brookite, arranged parallel to the basal plane. Before the blow pipe, fuses, yielding a magnetic mass. It is partly decomposed by hydrochloric acid. 
Augite. $\mathrm{CaMgSi}_{2} \mathrm{O}_{6}+(\mathrm{Mg}, \mathrm{Fe})(\mathrm{AlFe})_{2} \mathrm{Si}_{2} \mathrm{O}_{6}$

Monoclinic.

These crystals occur in short, thick prisms formed by the orthopinacurd (IOO), the prism (IIO), the clinopinacoid (OIO), and the pyramid (III), and in addition to these the orthodome (IOI), the base (OOI), the clinodome (O2I), and low pyramids. The nearly square columns often have corners truncated till a symmetrical eight-sided figure results. This eight-sided figure and the cleavage habit of augite are of prime importance in differentiating augite from hornblende. It occurs often coarsely or finely granular. The cleavage is distinct, parallel to the prism, and makes prism angles of $92^{\circ} 54^{\prime}$. Parting due to the twinning transverse to the $c$ axis is seen in lamellar masses. The fracture is uneven to conchoidal. The hardness is 5 to 6 and specific gravity 3 to 3.5. Luster is vitreous to resinous on fresh surfaces; color is usually green, brown, or black, and the streak a greenish grey, transparent to opaque. Under the microscope it shows but weak pleochroism. It has high relief, high interference colors, highest in sections parallel to the clinopinacoid. These sections give no optical figure in convergent light, show the cleavage marks parallel to the $c$ axis, and have an extinction angle of $35^{\circ}$ to $56^{\circ}$. Before the blowpipe augite melts to a glass which is dark because of the contained iron. It is not acted upon by acids. It is found in the slags of lime kilns and cement furnaces. The rocks in which it is found in this region are gabbro and diabase.

Hornblende. $\quad\left\{\mathrm{Ca}(\mathrm{Mg}, \mathrm{Fe})_{3}\left(\mathrm{Si} \mathrm{O}_{3}\right)_{4}\right.$ chiefly with

$\left\{\mathrm{Na}_{2} \mathrm{Al}_{2}\left(\mathrm{Si} \mathrm{O}_{3}\right)_{4}\right.$ and $(\mathrm{Mg}, \mathrm{Fe})_{2}(\mathrm{Al}, \mathrm{Fe})_{4} \mathrm{Si}_{2} \mathrm{O}_{12}$ Monoclinic

Crystals show but few planes. They are usually columnar or long slender prisms that give blades and sometimes are microscopic in fineness; forming flax-like fiber, rarely lamellar granular masses. The prisms have six sides instead of eight as augite has, and their cleavage, highly perfect, parallel to the prism, forms the characteristic angle of $124^{\circ}$. The fracture is from conchoidal to uneven. They are brittle, have a hardness of from 5 to 6 and specific gravity of 2.9 to 3.4 , varying with the amount of iron present. The luster is vitreous to pearly. The color, various shades of green or dark brown to black. Streak is paler than color. Opaque "to translucent. Under the microscope, strongly pleochroitic. High relief, high interference colors. In sections parallel to the clinopinacoid (OIO) there is no axial figure in convergent polarized light, the interference colors are highest and the extinction 
angle with the cleavage cracks is from $12^{\circ}$ to $15^{\circ}$, hence this is a good zone for distinguishing between hornblende and augite. The behavior of hornblende before the blowpipe resembles that of pyroxene. Hornblende readily changes to biotite. It has been made from an aqueous solution, but not yet successfully by smelting. It is found in furnace slags as an artificial product. It occurs in granites, cliorites, and gneisses. The rock mentioned above as being one of the the sources of magnetite is made up chiefly of hornblende.

Garnet. $(\mathrm{FeMg})_{3} \mathrm{Al}_{2}\left(\mathrm{SiO}_{4}\right)_{3}$

Regular.

In the clay pit of a brick yard at South Evanston are found fresh granite boulders and fragments of a black mica gneiss which contain large numbers of garnets. They are especially abundant in the gneiss.

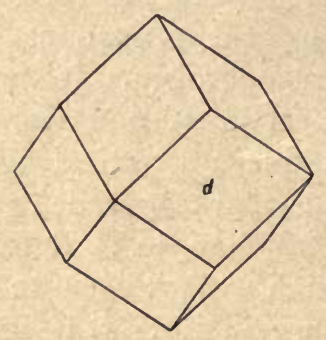

Fig. 16.

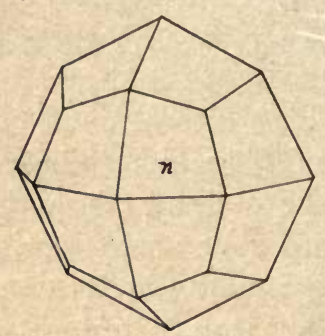

Fig. 17.

The grains show dodekahedral ( I IO) and trapezohedral (2II) planes (Figs. 16-17). They are usually irregular. No cleavage is seen, but there is a parting parallel to the dodekahedron (IIO). The fracture is subconchoidal to uneven. They are brittle and easily ground to powder. Their hardness is 6.5 to 7.5; specific gravity 3.15 to 4.3 ; luster resinous to vitreous. Of the various colors exhibited by garnet (red, brown, yellow, green, white and black) these specimens show only red and brown. The streak is white. Translucent. Under the microscope the high index of refraction (I.776) causes them to stand out from the neighboring minerals. Specimens examined showed normal isotropic qualities. These individuals fused easily to a brown glass, which is slightly magnetic. They decompose upon fusion with alkaline carbonates, and are then soluble in hot hydrochloric acid. To the same test for magnesium which was employed in the investigation of dolomite, after previous ignition, they gave very slight white precipitate of magnesium. A large amount of iron is present, and conse- 
quently our samples belong to the variety called almandite. None of the manganese, calcium, or chromium garnets have been found here.

Tourmaline. ( $\left.[\mathrm{AlO}]_{2}, \mathrm{Mg}, \mathrm{Fe}, \mathrm{Na}_{2}, \mathrm{Li}_{2}, \mathrm{H}_{2}\right)_{3}[\mathrm{AlO} \cdot \mathrm{B} \mathrm{O}]\left[\mathrm{Si} \mathrm{O}_{4}\right]_{2}$ (Groth)

Hexagonal

The representatives of this species in our region are more or less well crystallized in bedded or standing crystals in which the typical plane of tourmaline appears, as for example the rhombohedral ending to prisms which have three, six, and nine sides (Fig. I8).

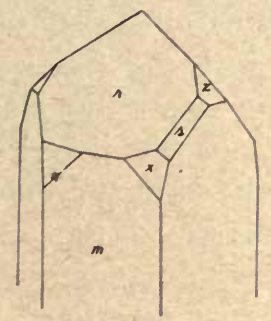

Fig. 18.

The crystals are usually slender, repeated, forming curved continuations of each other, or radiated groups. The prismatic faces are almost invariably strongly striated vertically. No distinct cleavage is found in tourmaline, but in slender crystals a parting transverse to the $c$ axis is evident. The fracture is subconchoidal to uneven. The tenacity brittle or friable, the hardness 7 to 7.5 and the s. g. 2.98 to 3.2 . The lustre is vitreous to resinous. The only colors that occur in the specimens of this region are black of a brownish or bluish shade. The streak is uncolored. They are opaque to transparent in thin sections. Under the microscope tourmaline is strongly dichroitic, and the absorption parallel to $c$ is greater than that parallel to $\pi . \Omega$ is dark blue to brown. $E$ is light blue. The polarization colors are brilliant, between a brown and a red. Before the blowpipe tourmaline fuses with difficulty, and is not decomposed by acids.

One of the readiest and most satisfactory means of distinguishing tourmaline from amphibole and pyroxene is to fuse on a platinum wire a mixture of the mineral with a like amount of acid potassium sulphate and fluorspar, when the boron green flame shows tourmaline. Its superior hardness, absence of cleavage, remarkable absorption when the $c$ axis is 
perpendicular to the vibration plane of the lower Nicol, help distinguish it from pyroxense, amphibole and biotite. The best specimens are those in the tourmaline granite specimen in which the gold was found.

The MICAS are represented by three varieties, muscovite, biotite and phlogopite. All have highly perfect basal cleavage, which makes it possible to separate them into extremely fine sheets, whose length and breadth is limited only by the diameter of the original crystal. They are elastic and similar in hardness and specific gravity, and all crystallize in the monoclinic system. All of them show on basal sections plane angles of $120^{\circ}$ and $60^{\circ}$, which suggests the hexagonal system, but under the microscope with convergent light and crossed Nicols, exhibit ellipses and hyperbolas characteristic of biaxial minerals.

The true nature of the optical phenomena of the micas is best seen in muscovite, in which the axial angle is $50^{\circ}$ to $70^{\circ}$. Biotite very closely resembles uniaxial minerals, the hyperbolas so nearly forming a single cross. These specimens show the percussion figures so characteristic of mica. When a cleavage plate is struck with a dull-pointed awl, a six-rayed figure results. In muscovite the most prominent crack is parallel to the clinopinacoid, and the plane of the optic axes is at right angles to it. In biotite the plane of the optic axes is parallel to the most prominent crack.

Muscovite. $\mathrm{H}_{2} \mathrm{~K} \mathrm{Al}_{3}\left(\mathrm{Si} \mathrm{O}_{4}\right)_{3}$.

Monoclinic.

Crystals usually tabular, with rhombic or regular six-sided outlines.

The planes are strongly striated horizontally, and the mineral usually occurs in scales and masses. Basal cleavage, perfect, while a secondary cleavage is shown by the percussion figures parallel to the clinopinacoid (oro) and this is the cause of the narrow strips in which the mineral often appears. The laminae are flexible and elastic. The hardness is 2.2 to 2.5 , the specific gravity 2.7 to 3 . The lustre is vitreous, pearly or silky. The colors, grey, brown, pale green, violet and yellow. The streak is uncolored; the diaphaneity, transparent to translucent. The pleochroism is feeble. The birefringence is high, hence interference colors are bright. Before the blowpipe with alkaline carbonates muscovite decomposes, giving reactions for iron and manganese. It yields water in a closed tube, 
and is unattacked by acids. Muscovite is the most common of the micas, since it is the most stable. Other forms, like biotite, decompose readily, and pass into muscovite. It is an essential constituent of mica schist, and a prominent constituent of gneisses.

Biotite. $(\mathrm{Al}, \mathrm{Fe})_{2}(\mathrm{Mg}, \mathrm{Fe})_{2}(\mathrm{~K}, \mathrm{H})_{2}\left(\mathrm{Si} \mathrm{O}_{4}\right)_{3}$

Monoclinic.

Crystal habit similar to that of muscovite. Often in scales disseminated through the containing rock, sometimes in massive aggregations. Cleavage plane is parallel to the base, and as in muscovite highly perfect. The planes of separation shown by percussion and gliding planes shown by pressure are similar to those of muscovite, but differently oriented in regard to the optic axes. The lustre is pearly to submetallic when black. The lateral surfaces, when smooth, are vitreous, the colors are always dark from green to black, deep black in thick crystals and even with thin laminae are brown with transmitted light. Transparent to opaque. Pleochroism strong on section at right angle to the base. Sections such as are common in petrographical slides parallel to the $c$ axis show a greater change of color than does hornblend being pale yellow to red for vibrations parallel to $c$ and brown for vibrations at right angles to this direction. Microscopic inclusions are often surrounded by pleochroitic halos. The axial plane parallel to the chief percussion line helps distinguish light-colored biotite from the darker shades of muscovite. Further, the axial angle is so small that this species often appears uniaxial. Before the blowpipe in a closed tube water is given off and on charcoal there is a strong reaction for iron. It is completely decomposed by sulphuric acid. Biotite is common in the granites and in the syenites and diorites of the region.

Phlogopite. Composition identical with biotite,

Monoclinic. save that the amount of $\mathrm{Fe}$ is always small.

The crystal habit of this mineral resembles that of biotite, and the same may be said of its cleavage, tenacity, hardness and lustre. It is somewhat lighter in weight, and much lighter in color, than biotite. It often has copper-like reflections from the cleavage surfaces, and exhibits a lustre varying from pearly to submetallic. Quite commonly it encloses regularly arranged microlites of epidote, augite, rutile needles, which form an angle of $60^{\circ}$ with each other, and cause star-like rays to appear when a section is viewed through transmitted light (asterism.) 
The pleochroism is distinct in colored varieties and the axial plane is arranged in the same manner with reference to the percussion figures. Its occurrence is similar to that of biotite.

\section{Vermiculites.}

When micas decompose, they give rise to hydrated silicates, which closely resemble the original mineral. These alteration products are placed by Dana in the group of VERMICULITES. They retain more or less perfect micaceous cleavage, but are without elasticity, and are softer than mica and of varying specific gravity. Usually they are of very low specific gravity. Their lustre is pearly or bronze-like, and their color yellow to brown, so that they are often brought into the laboratory as specimens of gold, in spite of the fact that the individual scales will float upon water. When heated to $100^{\circ} \mathrm{C}$, hygroscopic water is given off. When heated to $300^{\circ}$, another portion of water is given off. When the mineral is gradually heated, it opens out slowly, forming long worm-like masses.

Serpentine. $\mathrm{H}_{4} \mathrm{Mg}_{3} \mathrm{Si}_{2} \mathrm{O}_{9}$.

The decomposition of amphibole and pyroxene often produces finely fibrous, felted and cryptocrystalline granules of serpentine, which under the microscope appear translucent, greasy in lustre and feebly pleochroitic. The general physical properties of this mineral are not well represented in this region, since none of the massive forms appear.

Talc. $\mathrm{H}_{2} \mathrm{Mg}_{3}\left(\mathrm{Si} \mathrm{O}_{3}\right)_{4}$.

Associated with the fibers of serpentine are often found scales of talc, a sectile, flexible mineral, characterized by its greasy feeling, its softness which is I in the scale, and its. specific gravity of 2.7. Lustre on the cleavage surfaces is pearly. The color is white or green.

The Clay Group consists of soft earthy crystalline and amorphous minerals which in composition are chiefly hydrated silicates of aluminum. They are usually mixed with great quantities of foreign substances. The pure form of the hydrated aluminum silicate is kaolinite.

Kaolinite. $\mathrm{H}_{4} \mathrm{Al}_{2} \mathrm{Si}_{2} \mathrm{O}_{9}$.

Monoclinic.

This occurs rarely in small crystals. Sometimes it is in scales, usually in brown earthy masses. Cleavage unknown. 
Fracture earthy. Hardness, I. Specific gravity, 2.5. Color, white, reddish, yellowish, greenish. The feel is that which is called meager. It is plastic, being readily shaped when moist, and retaining its shape. Before the blowpipe it is infusible. It is slightly soluble in concentrated hydrochloric or sulphuric acid. It results from the decomposition of feldspar. The mixture of kaolinite with fragments of a great variety of rocks forms the material known as clay, of which we have such an extensive supply in this region.

\section{PHOSPHATES.}

Apatite. $\left\{\begin{array}{l}(\mathrm{C}, \mathrm{a}, \mathrm{F}) \mathrm{Ca}_{4}\left(\mathrm{P} \mathrm{O}_{4}\right)_{3} \text {. } \\ (\mathrm{Ca}, \mathrm{Cl}) \mathrm{Ca}_{4}\left(\mathrm{P} \mathrm{O}_{4}\right)_{3} .\end{array}\right.$

Hexagonal.

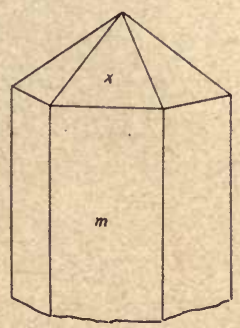

Fig. 19.

Crystals of apatite are common in argillaceous or in igneous and metamorphic rocks, and they occur also in sedimentaries. The planes most often seen are the prism (IOIO), modified by pyramids (IOIII) and by secondary pyramids (II $\overline{2} I$ ). The crystals are usually long thin needles, showing a parting transverse to the $c$ axis; that is, parallel to the base. . Fracture, conchoidal and uneven. Tenacity, brittle. Hardness, 5; specific gravity, 3.17; lustre, vitreous to subresinous; streak, white; color, sea green, bluish green, violet blue, yellow, red and brown. Transparent to opaque. Under the microscope colored varieties show slight dichroism. The moderate refraction of apatite gives, under the microscope, but a medium relief. Its double refraction is very low, and the axial cross can be seen in convergent light with difficulty. The interference colors are dull, not above grey of the first order. The columnar crystals show parallel extinction, and are broken at right angles to the $c$ axis. Apatite colors the Bunsen flame reddish yellow, showing calcium; and when moistened by sulphuric acid, a pale bluish green results from the phosphoric acid present. It dissolves in hydrochloric and nitric acid, but 
without effervescence. Apatite occurs in minute microscopic crystals in nearly all the igneous rocks, and especially in granite. It is one of the earliest products of crystallization. In comparison to the mass of the other mineral constituents of the rock it is so small that in none of the specimens examined does it occupy a more important place than that of an accessory mineral.

\section{SULPHATES.}

The Sulphates are represented by two species in the normal hydrous group, namely, gypsum and melanterite.

Gypsum. $\mathrm{CaSO}_{4}+2 \mathrm{H}_{2} \mathrm{O}$.

Monoclinic.

This mineral, which is the most abundant of all the sulphates, is represented by well formed crystals and groups of crystals in the clay beds. A fine group now in the Field Columbian Museum, was found by Mr. Duane Doty at Pullman, Ill. A photograph of a single crystal is given in pl. X.

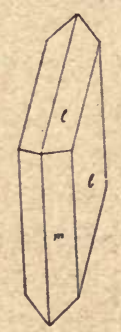

Fig. 20.

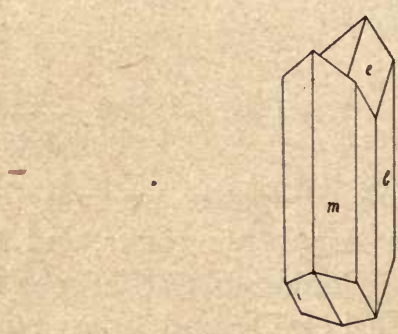

Fig. 2I.

It is a clear, transparent crystal $2 \frac{1}{2}$ inches long, which began its crystallization around a string of material that has the appearance of some organic matter. Goniometric measurements were possible and give $I^{1} I^{\Lambda} I \bar{I} I 36^{\circ} ; I^{\Lambda} I \bar{I} O$ $68^{\circ}$. Fig. 21 represents a common twinned form in which the twinning plane is parallel to the orthopinacoid. Another common twin is one parallel to the orthodome, and when the pyramid planes are bent, the so-called swallow-tail twin results. The groups in clay are stellate, radiated, and in globular form. The pyramid and orthodome planes are often rounded by repetition of these faces. The cleavage parallel to the clinopinacoid (O10) is very perfect, so that this plane shows a pearly lustre. Parallel to the orthodome the cleavage is so perfect that crystals are often full of cracks in this direction, and consequently present a fibrous appearance and a silky 
lustre. These two directions of perfect cleavage assist materially in the orientation of a crystal. There are two other directions of incomplete cleavage, one parallel to the orthopinacoid and the other parallel to the steep orthodome (IO3). The hardness of gypsum is 1.5 to 2.0 . The specific gravity is 2.3 , lustre parallel to the clinopinacoid, pearly and shiny, parallel to other surfaces subvitreous, massive varieties dull, colorless, white, brown, yellow, blue; streak white; transparent to opaque. Yields water in a closed tube, fuses easily at 3 in the scale of fusibility, coloring the flame a reddish yellow. Heated to a temperature not above $260^{\circ} \mathrm{C}$ forms plaster of paris, which upon moistening with water again becomes solid. Soluble in hydrochloric acid. These crystals were formed by the decomposition of the marcasite in the clay probably in a manner shown by the formula $\mathrm{Fe} \mathrm{S}_{2}+\mathrm{CaCO}_{3}+3 \mathrm{H}_{2} \mathrm{O}+7 \mathrm{O}=\mathrm{CaSO}_{4}$. $2 \mathrm{H}_{2} \mathrm{O}+\mathrm{Fe} \mathrm{CO}_{3}+\mathrm{H}_{2} \mathrm{SO}_{4}$.

Melanterite. $\mathrm{FeSO}_{4}+7 \mathrm{H}_{2} \mathrm{O}$.

Monoclinic.

This sulphate is a direct result of the oxidation of iron sulphide in the presence of water. Commercially it is known as copperas, or iron vitriol. The crystals observed in the museums where iron sulphides are gradually disintegrating are usually fibrous, capillary and stalactitic at first, and subsequently, by drying, pulverulent. Fracture, conchoidal; brittle; hardness 2; specific gravity, I.89; luster vitreous; color, green, yellowish on exposure, white; streak uncolored; subtransparent to translucent. Taste, sweetish, astringent, metallic. Easily soluble in water; melts in its water of crystallization, leaving behind a white mass which, when roasted before the blowpipe, yields red iron oxide.

CLASS VII. SALTS OF ORGANIC ACIDS.

This small and unimportant class is not represented in this region.

\section{CLASS VIII. HYDROCARBON COMPOUNDS.}

Of the Hydrocarbon Compounds there are at least four representatives.

\section{Natural Gas.}

At various places in the vicinity small quantities of natural gas escape from wells, cellars, and other excavations. At Edgewater a gentleman capped his drinking water well, 
piped the escaping gas to his kitchen stove, and has for ten years been using the gas for cooking purposes. Occasionally small pockets of gas are found while boring artesian wells or making large excavations. Passengers on the C. \& N. W. R'y between Evanston and Chicago saw, during the summer of I899, a gas well burning for several weeks. The presence of small quantities of gas is to be expected in the limestone of this region, since the residual products in the decomposition of organic matter (asphalt, etc.) are so much in evidence. Further, the limestone is similar in character to the Trenton limestone, which is the great repository of the Ohio and Indiana oil fields, inasmuch as it is a porous magnesium limestone and is slightly elevated in a long monocline. Underlying it are bituminous shales. Thus we have lacking only one structural condition necessary for an oil field, and that is a protecting cover. Natural gas is composed almost wholly of marsh gas $\left(\mathrm{CH}_{4}\right)$. It contains also olefiant gas $\left(\mathrm{C}_{2} \mathrm{H}_{2}\right)$, besides free hydrogen, nitrogen, oxygen, carbon dioxide, carbon monoxide, and sulphuretted hydrogen.

\section{Petroleum.}

Diffused and distributed through the underlying Niagara is a viscous reddish brown oil of rather high specific gravity. One one-thousandth of one percent of oil distributed through the rock of a section as thick as the N iagara limestone (300 feet) according to the method of calculation of Orton (Annual Rep. U. S. G. S., I886, Part II. p. 507) would yield I 50,000 barrels of oil to the square mile, and Hunt (Chem. and Geo Essays, p. 173) estimated that the limestone underlying this area contains ${ }^{\circ}$ even more oil than the above figures represent. According to his calculation there are over seven millon barrels per square mile. This oil is indigenous.

\section{Asphalt and Maltha.}

The presence of asphalt in the limestone of the region has long been noted. Twenty-five years ago it was the subject of comment by Hunt (loc. cit.). - It gives to the stone a soiled appearance which quarrymen have tried to turn to a virtue instead of a blemish by claiming that when in a building it softens the color and gives an air of stability and dignity to a stone which otherwise would show too strong a glare of white. Visitors at the Stony Island quarry often think that the black soft masses which, heated by the sun, run down the sides of 
the wall are coal tar or some similar artificial product. One of the best means of distinguishing coal tar and asphalt is to dissolve pieces in carbon disulphide, evaporate, put I gramme in 5 c. c. fuming sulphuric acid for 24 hours, dilute to twice the volume. Coal tar gives a very dark brown solution, and the Stony Island asphalt gives a faintly colored solution. The percentage of asphalt is too small to increase the value of this rock as a road metal. In some localities the asphalt is collected in cavities formed by the dissolution of fossil coelenterates, echinoderms, molluscs, etc., as at Stony Island. A large number of pieces of seemingly pure asphalt were taken, and from them four analyses made. I hey showed $15 \%$ of mineral matter, $82 \%$ of bituminous matter soluble in carbon disulphide and $2 \%$ of nonbituminous matter. Carbon disulphide is taken to dissolve the bitumen. Organic matter left is regarded as nonbituminous, and may be separated from mineral water by ignition. If this nonbituminous matter is present in large quantities, it spoils asphalt for commercial use, since it is liable to decomposition. Stony Island asphalt has a very small percent (2.16). Two-thirds of the mineral matter remaining is soluble in hydrochloric acid $\left(\mathrm{CaCO}_{3}\right.$ and $\left.\mathrm{Fe}_{2} \mathrm{O}_{3}\right)$ and of the remainder the major part is sand. The bituminous matter is again separated. That portion which is soluble in petroleum spirit is called petrolene. This is regarded as a solvent of asphaltene. Asphaltene is that portion which is soluble in boiling turpentine. The amount of petrolene in Stony Island asphalt is small. Maltha is the name given to the semi-fluid asphalt. The following table presents for comparison some analyses of asphalts from four different regions:

\begin{tabular}{|c|c|c|c|c|}
\hline SOURCE. & $\begin{array}{l}\text { Bituminous } \\
\text { organic } \\
\text { matter. }\end{array}$ & $\begin{array}{l}\text { Nonbitumin- } \\
\text { ous organic } \\
\text { matter. }\end{array}$ & $\begin{array}{c}\text { Mineral } \\
\text { matters }\end{array}$ & Authority. \\
\hline $\begin{array}{l}\text { Trinidad ........ } \\
\text { Bermuda ...... } \\
\text { California...... } \\
\text { Chicago ....... }\end{array}$ & $\begin{array}{l}54.25 \\
94.75 \\
98.26 \\
82.00\end{array}$ & $\begin{array}{l}\text { 9. } 24 \% \\
160 \\
\text { 2. } 16\end{array}$ & $\begin{array}{c}36.51 \% \\
3.65 \\
1.74 \\
15.80\end{array}$ & $\begin{array}{l}\text { Richardson. } \\
\text { Richardson. } \\
\text { Tillson. } \\
\text { Crook. }\end{array}$ \\
\hline
\end{tabular}

\section{Peat.}

Under the gravel and above the clay throughout a large part of the region is found a layer of peat and impure lignite. It occurs in beds and pockets, rather than a continuous sheet. It can be seen in many places where excavations are being 
made for buildings, quarries, etc., and along the lake shore. It differs from true coal inasmuch as it lacks homogeneity and has a greater part of its vegetable fibers but partially altered. When changed by pressure, it loses a part of its more volatile constituents, becomes more thoroughly consolidated and homogeneous, and passes into lignite. Peat is without crystal structure, retaining, as it does, the original cell structure. It is somewhat brittle, has a hardness of from 0.5 to 2 , and a specific gravity of from I to I.8. It is brown in color and opaque. 


\section{SUMMARY.}

There are more than fifty mineral species in this region. Of these, twenty are indigenous. That is, they are not due to the transporting power of glaciers. They may most truly be considered to represent the mineralogy of regions whose rock floor is formed by the Niagara limestone. They are sulphur, galena, sphalerite, millerite, pyrite, marcasite, quartz, hematite, limonite, calcite, dolomite, siderite, aragonite, kaolinite, gypsum, melanterite, gas, petroleum, asphalt and lignite. Of these the hydrocarbons and sulphur, gypsum and melanterite arise from chemical changes through which other substances have passed. Whether the hydrocarbons of the region come from the decomposition and destructive distillation of plants or of animal remains or of both is not known. Possibly an analysis of the oil for free nitrogen and sulphur might shed some light upon the question, since a high percent of these elements is thought to suggest an animal origin. An examination of the shales which contain them, possibly the Hudson River shales, might give some indication. The sulphur, gypsum and melanterite arise wholly or in part from the decomposition of that very common mineral, marcasite. Marcasite is very well represented here, both as to its crystallography, its chemistry and its mode of occurrence. Its great abundance in positions where there is reason to think that its crystallization was rapid lead to the conclusion that the more stable form of the iron sulphide represents that crystallization which is dependent upon favorable conditions. The occurrence of millerite in sphalerite is to be noted. A general survey of the mineral composition of the surrounding country gives a suggestion that the amount of silica in the earth's crust as commonly recorded, has been overestimated. 


\section{LITERATURE.}

The literature on the minerals of this area is very meager. Reference has been made to the following:

Andrews, Dr. Edmund; Transactions Chicago Academy of Sciences.

Bannister, H. M.; Economical Geol. of Ill., Vol. II, I882.

Guthrie, Ossian; Relics Turned Up in Drainage Canal.

Hobbs, Prof. Wm. H.; Diamond Field of the Great Lakes. Journal of Geology, Vol. VII., No. 4, 1899.

Leverett, Frank; Plestocene Features and Deposits Chicago Area.

Chicago Acad. Sci., Bull. II., I897.

Leverett, Frank; Water Resources of Ills.

On U. S. G. G. R., Vol. XVII.,, Pt. II.

Worthen, A. H.; Economical Geology of Ills., Vol. I. 


\section{INDEX.}

Amphibole ............... 42

Andrews .................. 3

Apatite ................ 49

Aragonite ................. 37

Argentite ................ 21

Asphalt ................... 52

Augite .................. 43

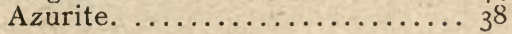

Bauerman ............... 33

Biotite...............46, 47

Bridgeport .............. II

Bunsen.................. 22

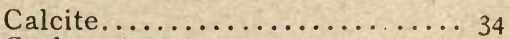

Carbonates................. 34

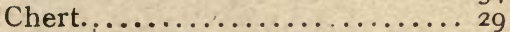

Conditions favoring study of Cook Co. minerals ............... I5

Copper..................... 20

Corundum .................... 31

Cuprite......................... 30

Dana...........16, 22, 30, 33, 4I

Diamond................. I7

Dikes................... I I

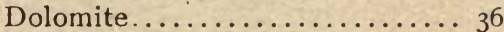

Drainage Canal................. I9, 27

Economical Geol. of Illinois..... 36

Elements................ I7

Emigrant minerals ........... I2

Evanston .........12, 15, 26, 31, 52

Fahlbänder ................ 26

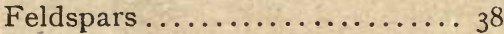

Galena................. 2I

Garnet.................... 44

Gas.................... 5 I

Gold................... Ig

Graphite................. I 7

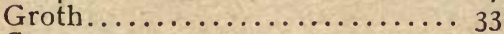

Gypsum....................... 53

Haloids .................. 27

Hematite .............. 3 I

Hintze...............4 I, 42

Hobbs ..................... 17

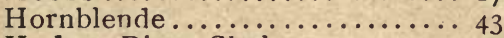

Hudson River Shale......... I , 55

Hunt.................... 52

Hydrocarbon compounds ....... 5 $5^{\text {I }}$

Hypersthene............. 42

Ilmenite...............

Interest in the subject.........

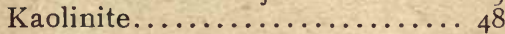

Klochmann............... 33

Lacroix ...............22, 23

Leverett ................ I I, I2

Localities ................. I5

Magnesian Limestone......... II

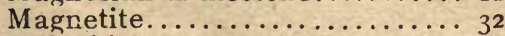

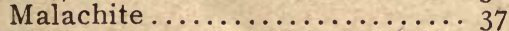

Mallard ..................

Maltha................ 52
PAGE

Marcasite............... 24

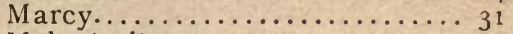

Melanterite .............. 5 I

Metamorphic phenomena....... 12

Methods of estimating quantity of minerals ............... I2

Methods of collecting minerals.. 15

Mica................... 46

Microcline .............. 4'

Microperthite............. 40

Muscovite................. 46

Natural Gas................ 5 I

Naumann ...............22, 33

Niagara formation........... II, 12

Ordovician ............... I I

Organic acids ............. 5 I

Orton .................... 52

Oxides................... 27

Oxygen Salts................ 34

Peat .................. 53

Petroleum .............. 52

Phlogopite ................ 46

Phosphates ............... 49

Plagioclase .............. 4 I

Pyrite ................. 23

Pyroxene .................. 42

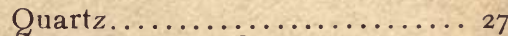

" amount of ............ 12

impurities in ......... 29

Relation of Cook Co. Mineralogy to the science of $M$ ineralogy ... 9

Result of recrystallizing materials composing mud ........... g

Rocks of the region......... I 1, I2

Ruskin .................. 9

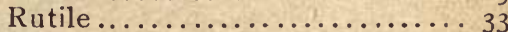

Serpentine ............... 48

Siderite ................ 37

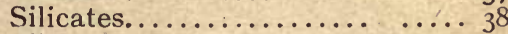

Silicon...............13, 20, 29

Solubilitv of Minerals .......... 12

Source of Minerals .......... I2

Sphalerite .............. 22

Species to be expected.......... II

Stony Island............... I I

St. Peter Sandstone........... II

Sulphates................. 50

Sulphides ................. 20

Sulpho-salts............... 27

Sulphur.................. 17

Szabo.................. $4 \mathrm{I}$

Talc .................. 48

Tourmaline .............. 45

Trenton I_imestone........... II

Tschermak ................. 33, 40

Vermiculites ............... 48

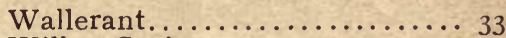

Willow Springs ............ 27 



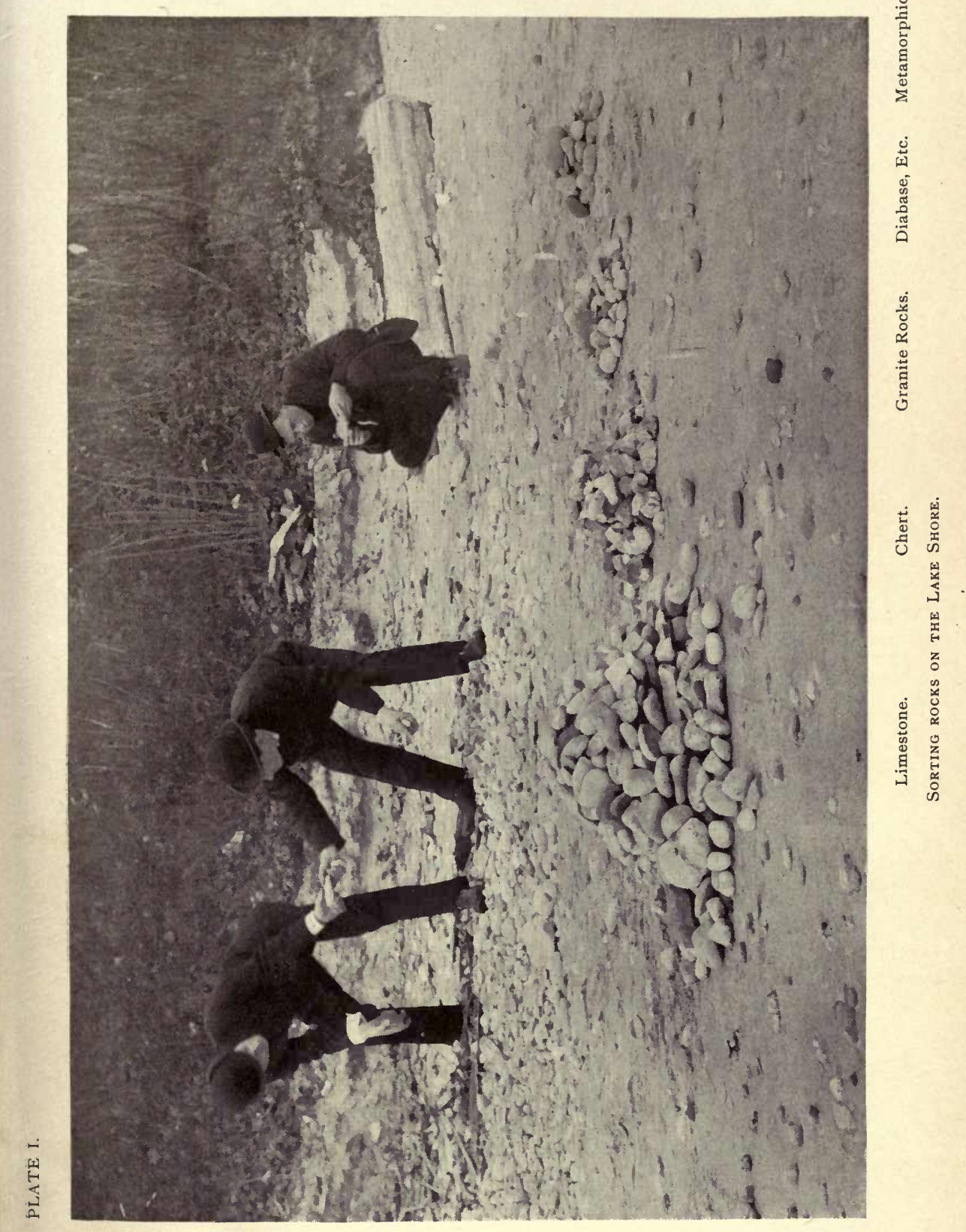




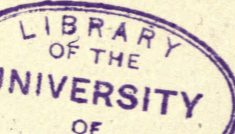




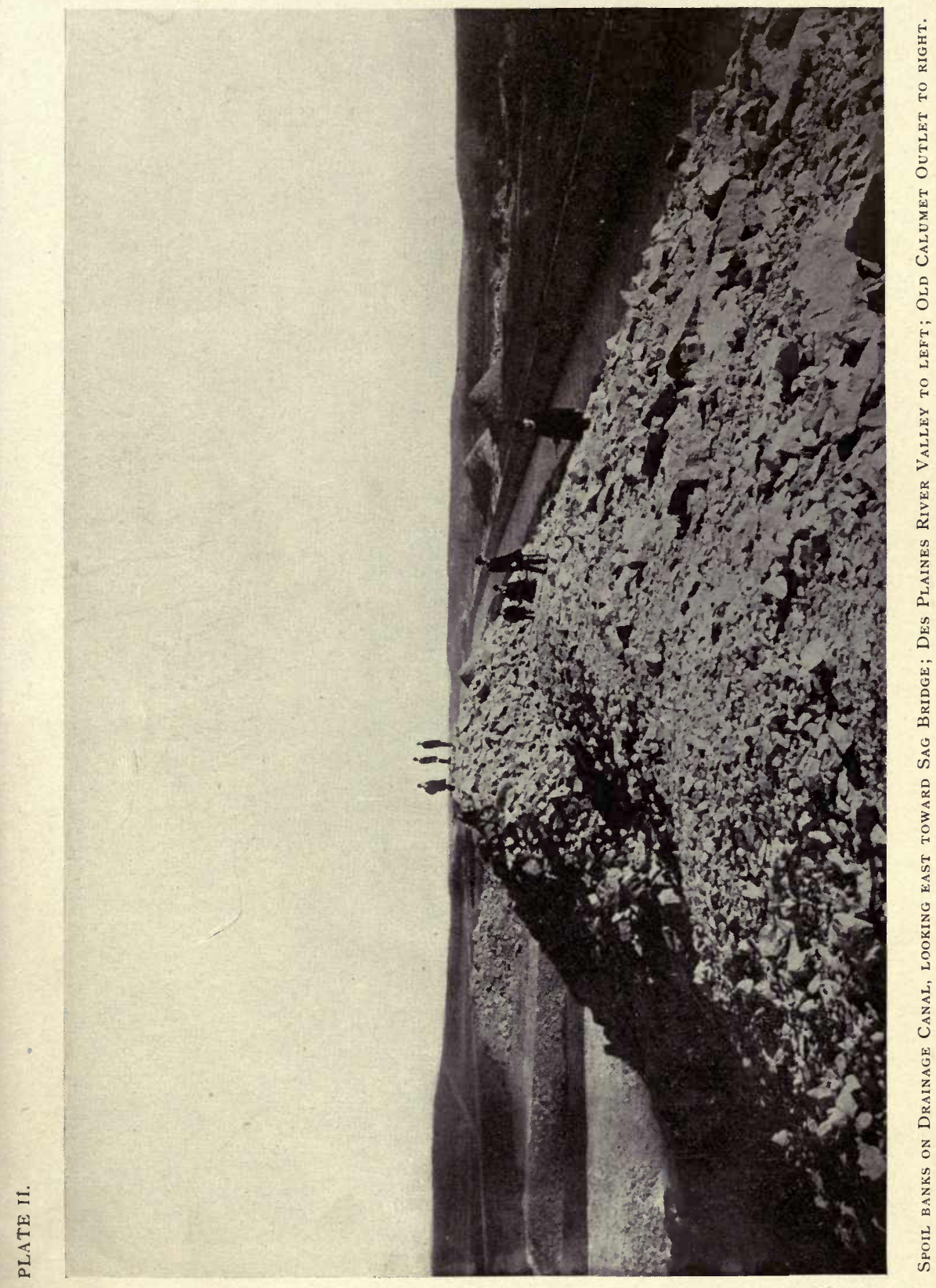


- 


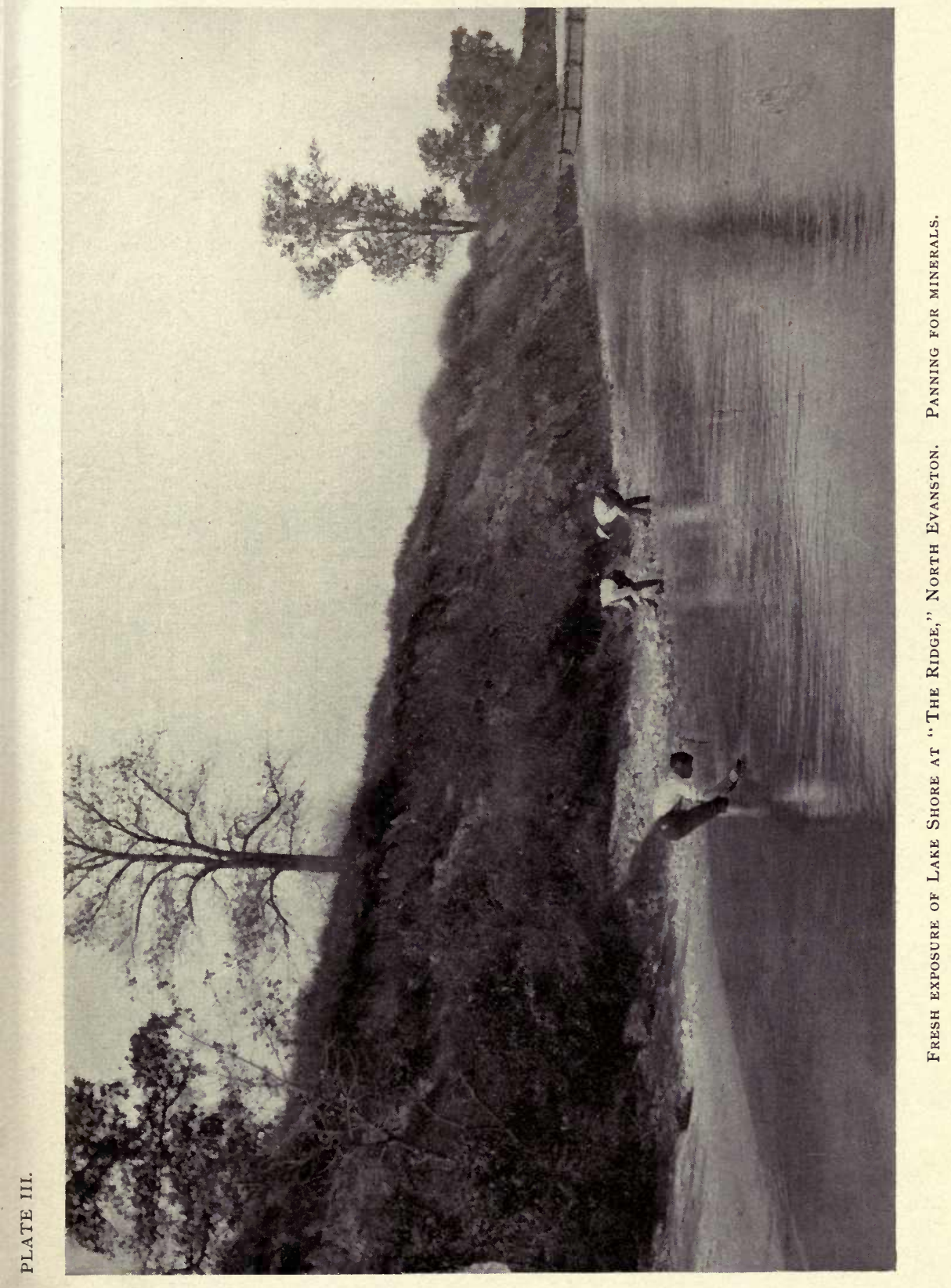


$\theta$ 


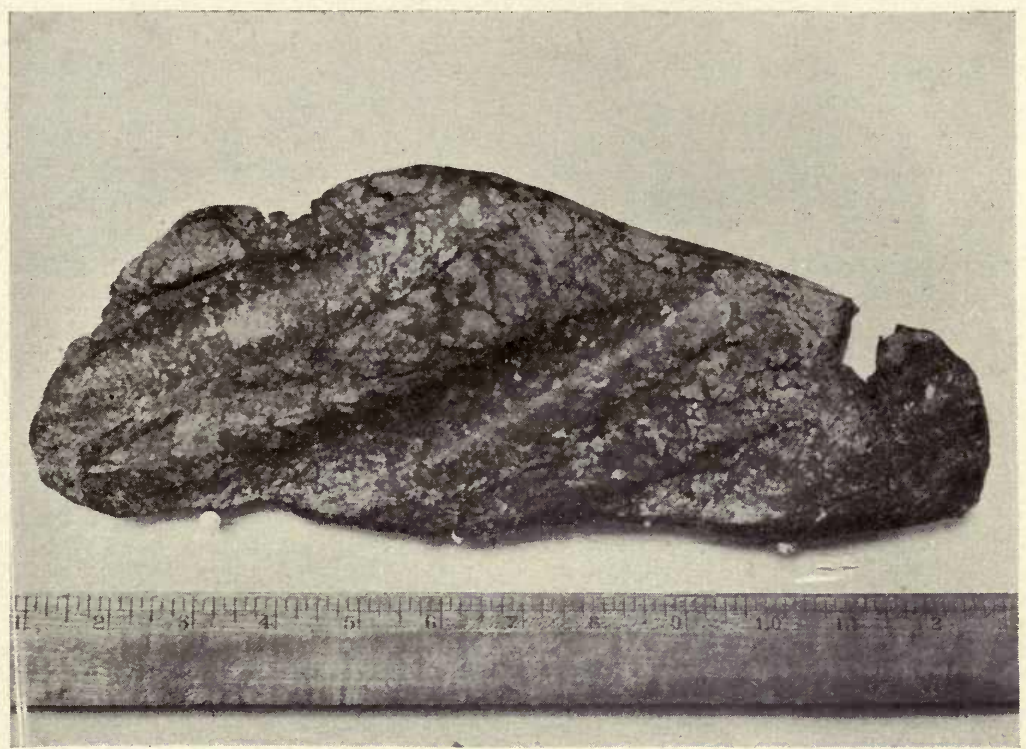

Fig. i. Copper found at Worth, Ill.; Weight, 13 Lbs.; Partly crushed in Stone crusher; Now owned by Ossian Guthrie.

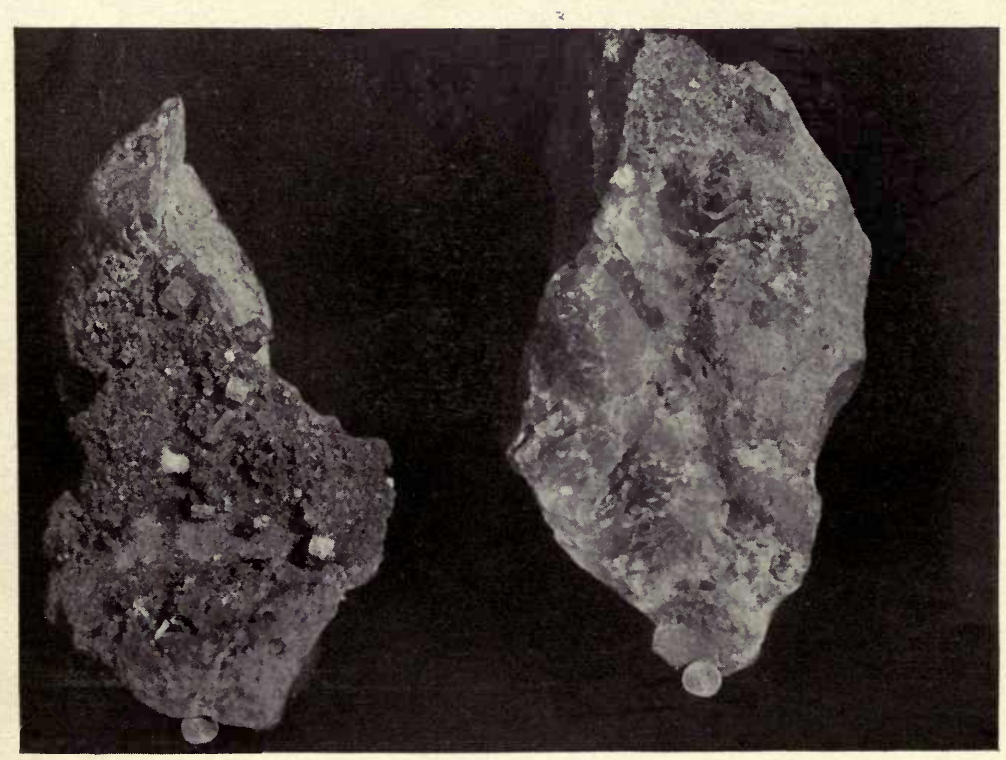

Fig. 2. Crystals of Pyrites in Niagara limestone; Exposed in left hand SPECIMEN BY DISSOLVING AWAY THE LIMESTONE IN HYDROCHLORIC ACID. 
LIBAAP

UNIVERSITY

C. OF

CLIFORNIA 


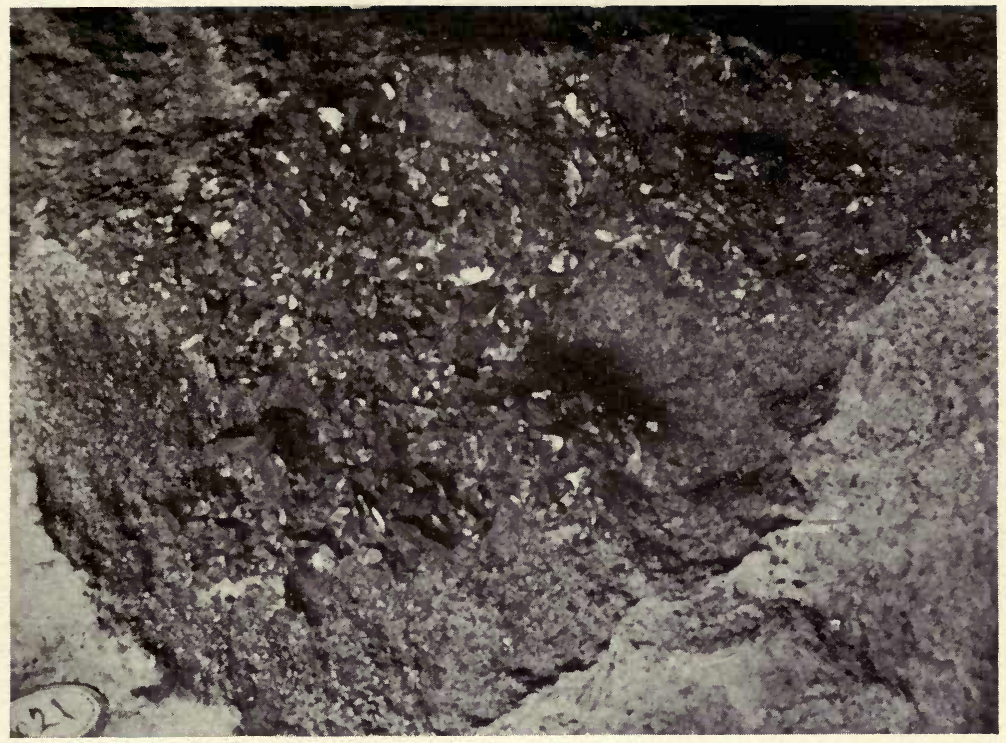

Fig. I. Marcasite of the variety known as "Spearhead Pyrites" on limestone FROM BRIDGEPORT QUARRY.

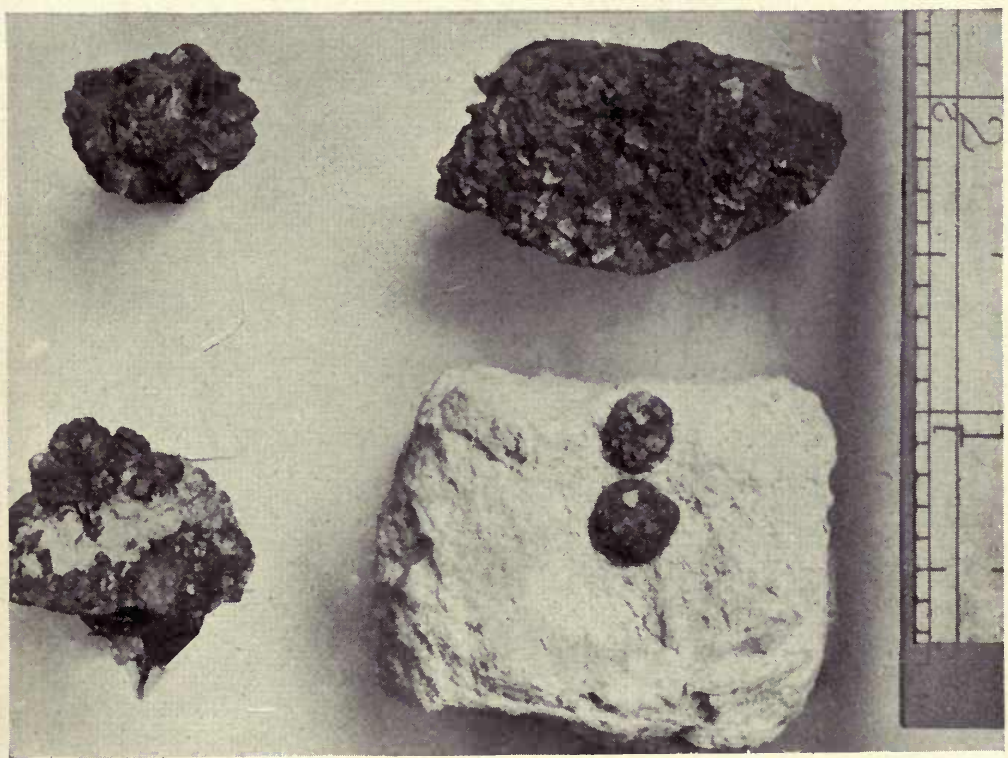

Fig. 2. Marcasite; Two upper specimens are of the variety known as "Cockscomb Pyrites;" Left-hand lower specimen contains many striated clinodome PLANES; RIGHT-HAND LOWER SPECIMEN SHOWS GLOBULAR MASSES in Niagara Limestone. 
8 
PLATE VI.

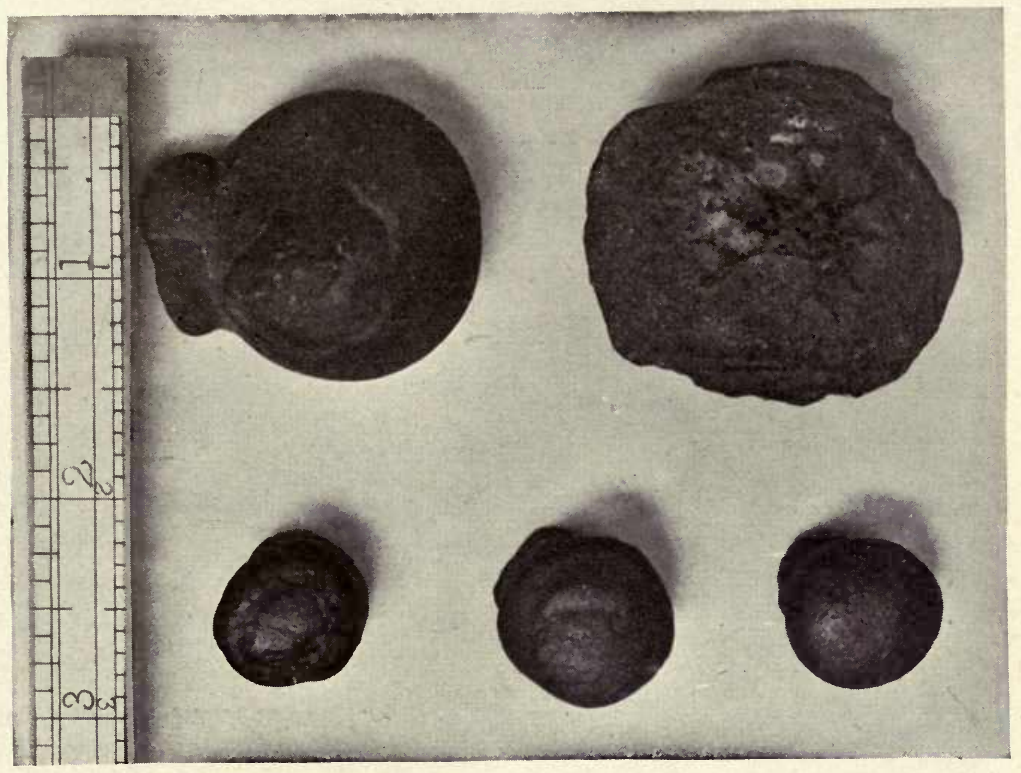

Fig. i. Marcasite pebble from the Lake Shore.
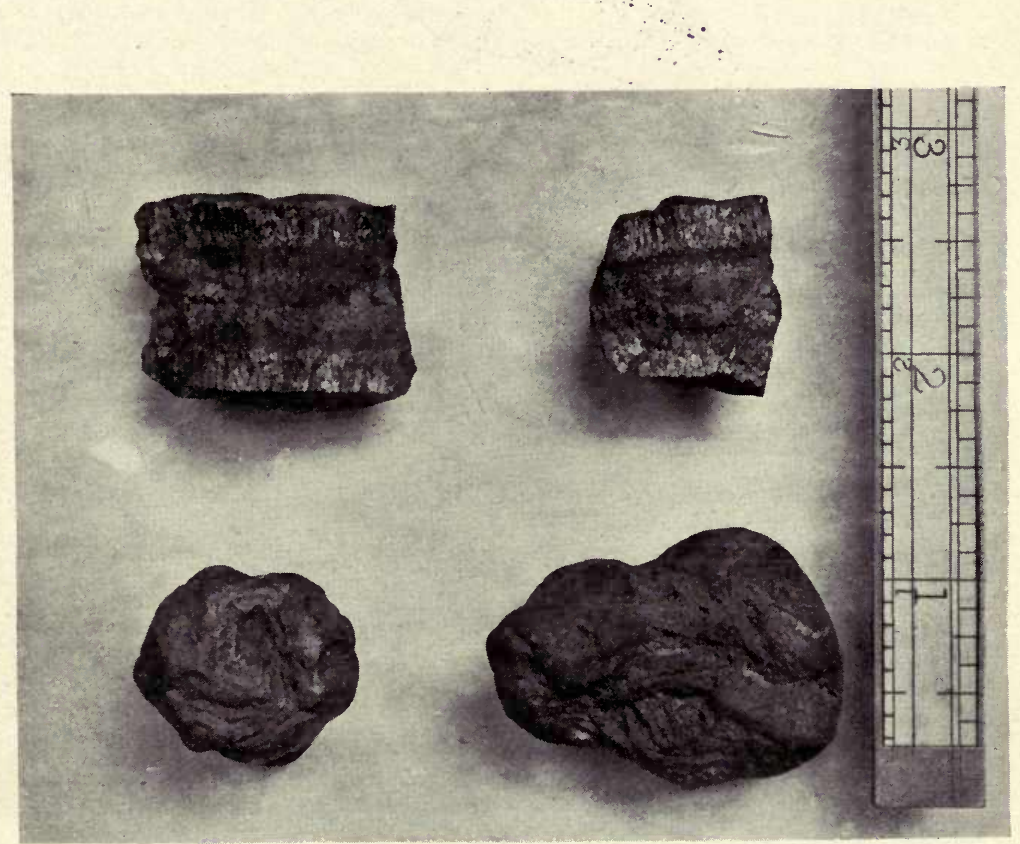

Fig. 2. Marcasite pebbles; Crystal planes still evident in two lower specimens; TWO UPPER SHOW ACICULAR CRYSTALS BORDERING CORE OF GRANULAR MARCASITE, THUS FORMING NODULES. 


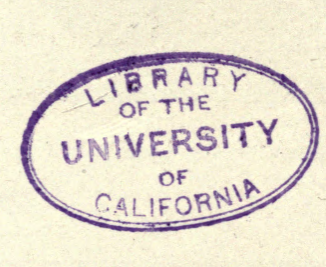




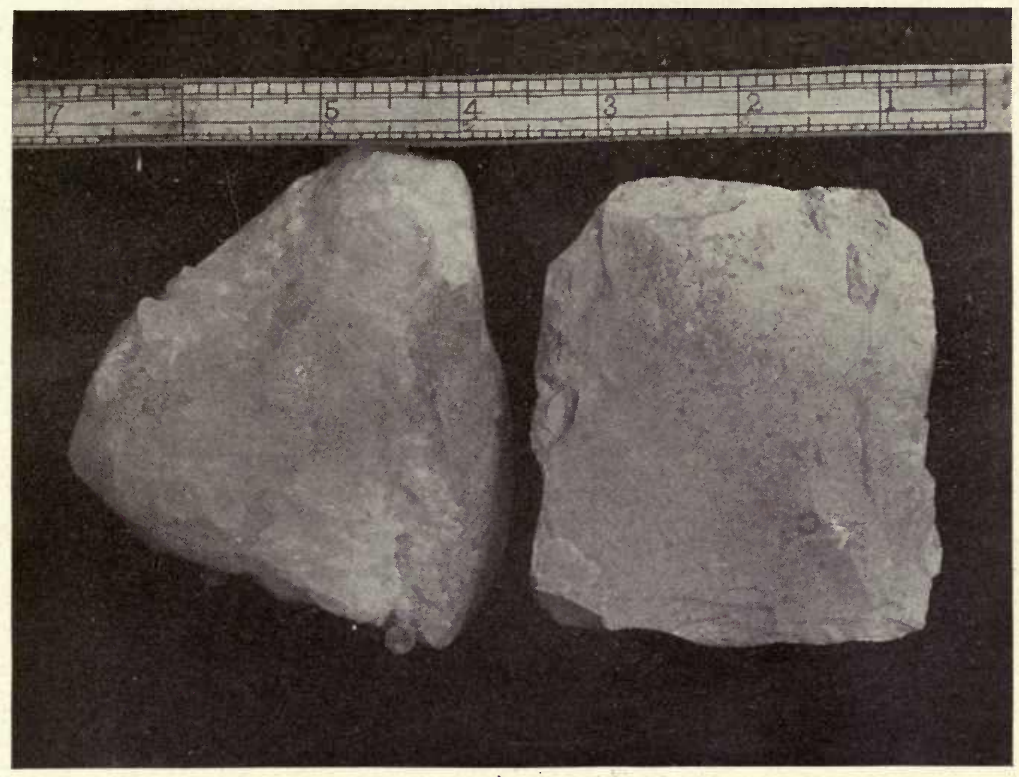

Fig. I. Common crystalline Quartz at left; Chert at, Right Showing crinoid STEMS AND OTHER ORGANIC'Agents ACtive. in ITS Formation.

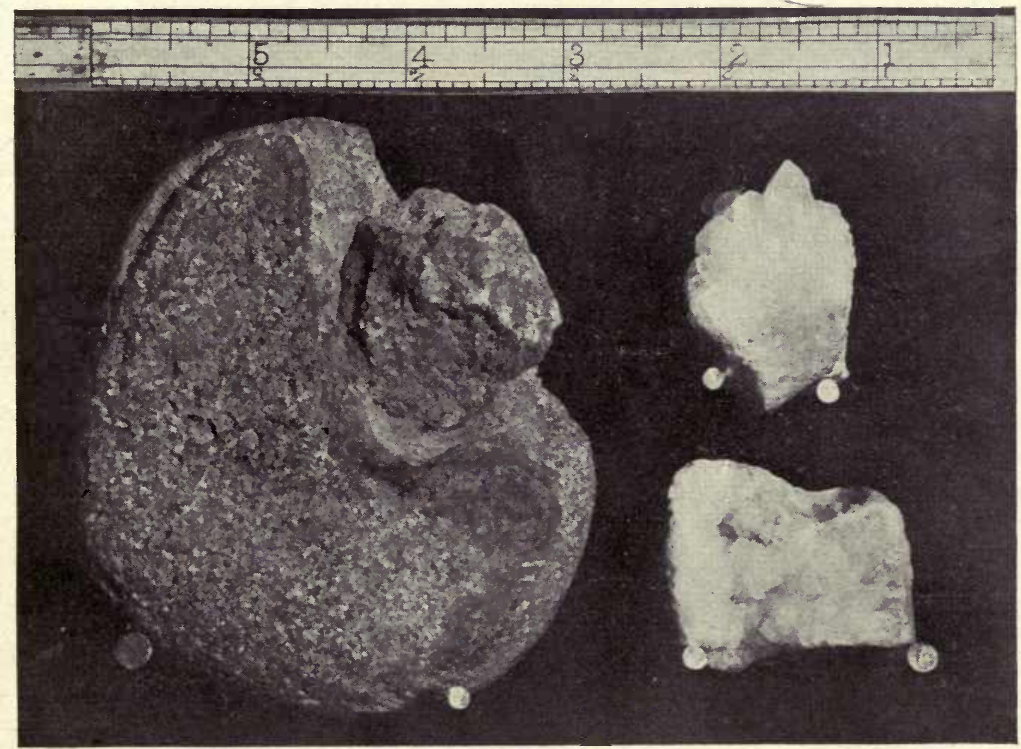

Fig. 2. Geode in Niagara limestone at left; Quartz crystals at right; Upper SPECIMEN SHOWS PRISMS CAPPED BY RHOMBOHEDRONS. 



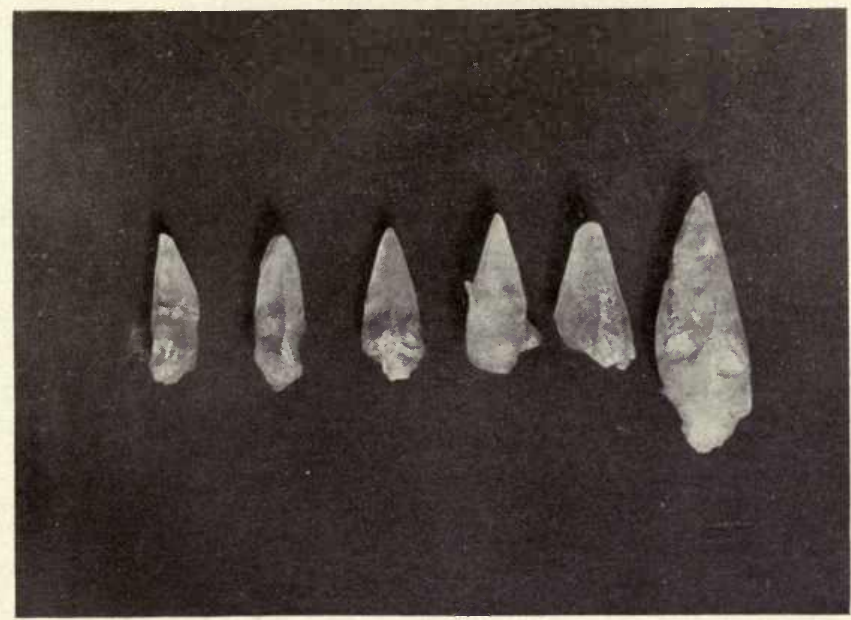

Fig. I. Calcite scalenohedrons, Natural Size; from Stony Island.

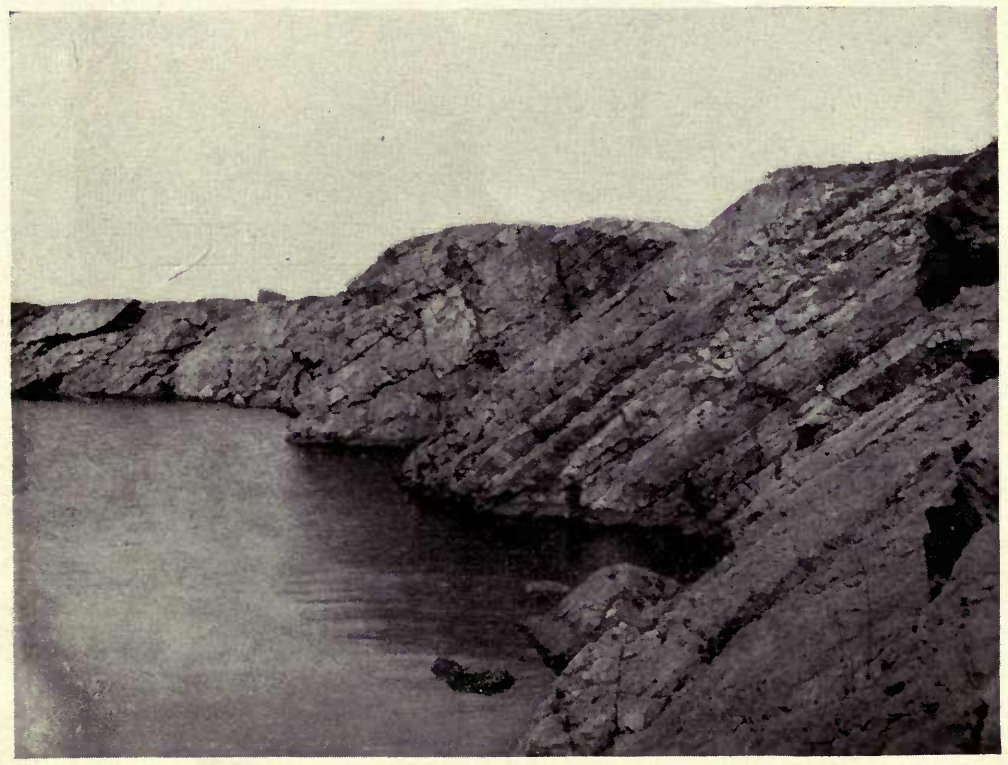

Fig. 2. East wall of Stony Island QUarry, Looking North. 
E 
PLATE IX.

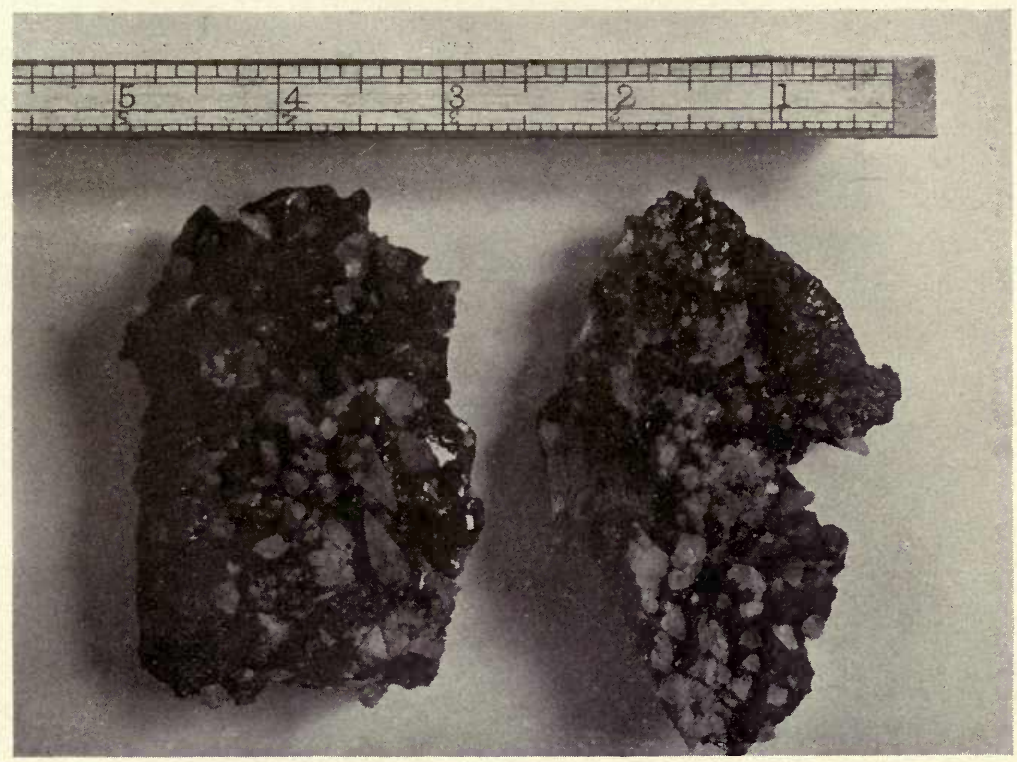

Fig. I. Calcite scalenohedrons in Asphalt on Niagara Limestone from Stony Island.
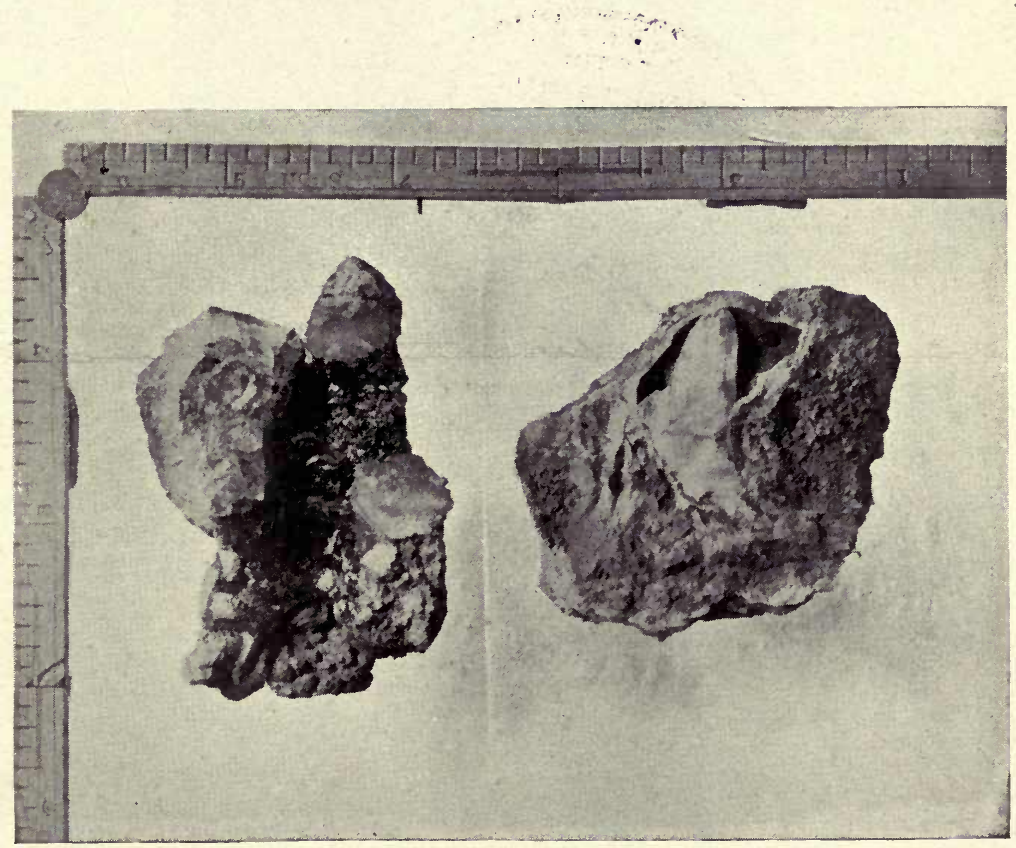

Fig. 2. Calcite and Asphalt on Limestone from Stony Island; in Right-hand SPECimen Calcite occupies Cavity formed by a Zaphrentis. 
$\theta$ 
PLATE X.

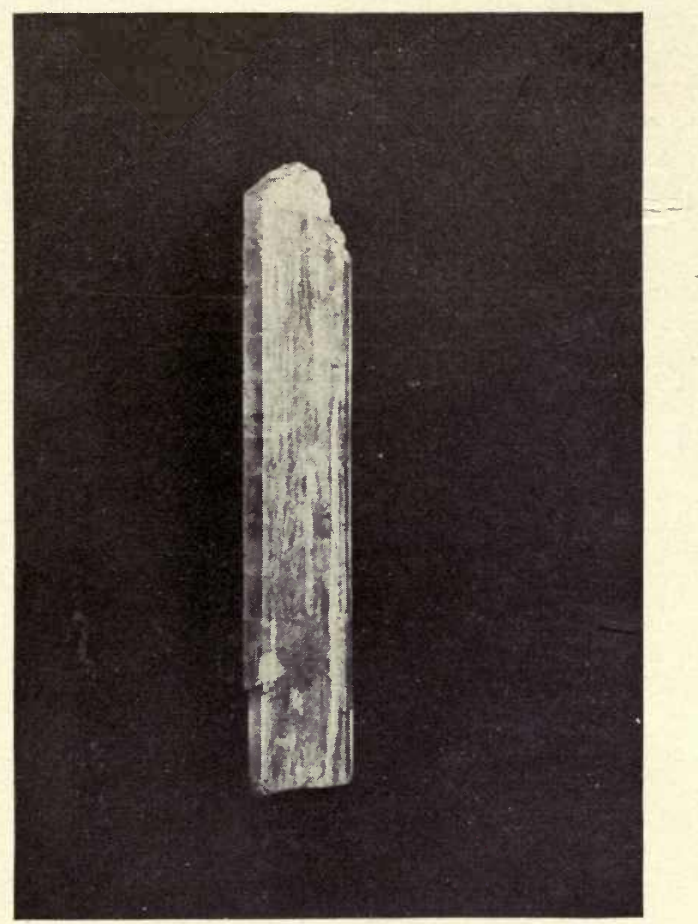

Gypsum crystal from Pullman, Ill.; Natural sizf; now in Field Columbian Museum. 






\section{DAY USE \\ RETURN TO DESK FROM WHICH BORROWED LOAN DEPT.}

This book is due on the last date stamped below, or on the date to which renewed.

Renewed books are subject to immediate recall.

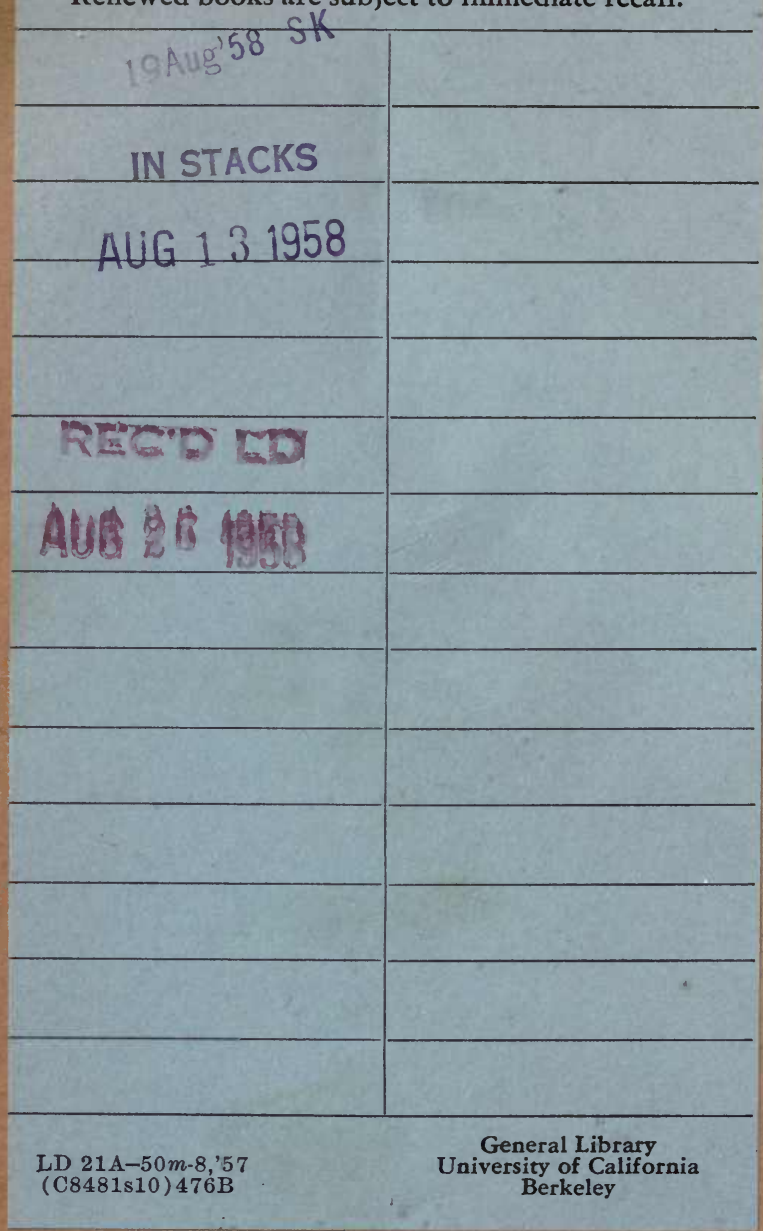




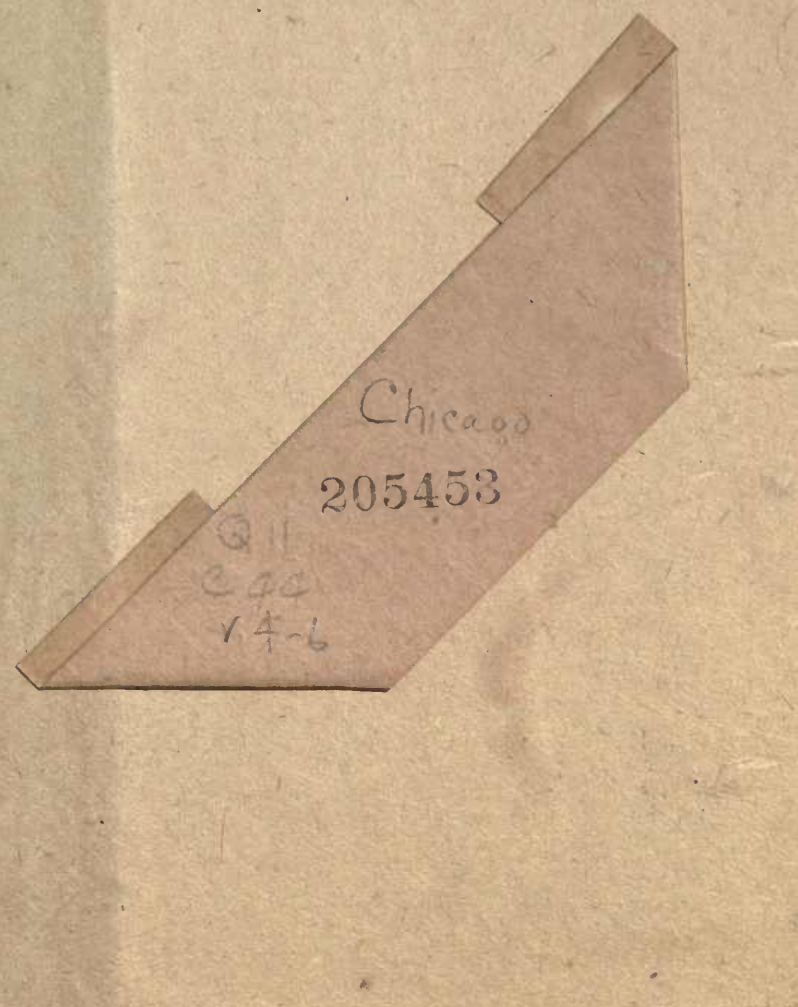


